US Army Corps of Engineers ${ }_{\circledast}$

Engineer Research and

Development Center

Flood and Coastal Systems Program

\title{
Implementation of Flexible Vegetation into CSHORE for Modeling Wave Attenuation
}

Yan Ding, Q. Jim Chen, Ling Zhu, Julie Dean Rosati, and

February 2022

Bradley D. Johnson

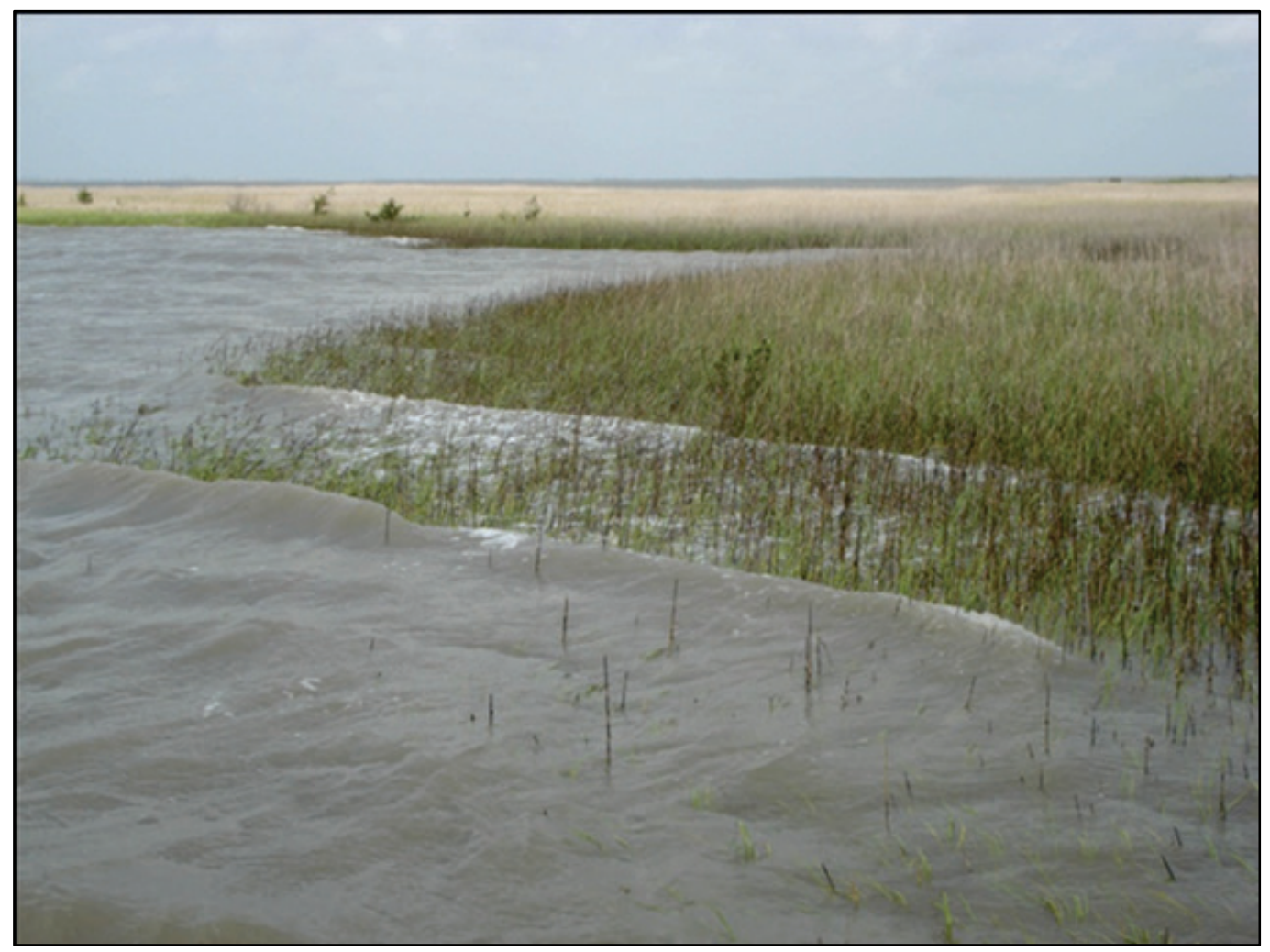


The US Army Engineer Research and Development Center (ERDC) solves the nation's toughest engineering and environmental challenges. ERDC develops innovative solutions in civil and military engineering, geospatial sciences, water resources, and environmental sciences for the Army, the Department of Defense, civilian agencies, and our nation's public good. Find out more at www.erdc.usace.army.mil.

To search for other technical reports published by ERDC, visit the ERDC online library at https://erdclibrary.on.worldcat.org/discovery. 


\title{
Implementation of Flexible Vegetation into CSHORE for Modeling Wave Attenuation
}

\author{
Yan Ding, Julie Dean Rosati, and Bradley D. Johnson \\ Coastal and Hydraulics Laboratory \\ US Army Engineer Research and Development Center \\ 3909 Halls Ferry Road \\ Vicksburg, MS 39180-6199 \\ Q. Jim Chen and Ling Zhu \\ Department of Civil and Environmental Engineering and \\ Department of Marine and Environmental Sciences \\ Northeastern University \\ 471 Snell Engineering Center \\ 360 Huntington Ave. \\ Boston, MA 02115
}

Final report

Approved for public release; distribution is unlimited.

Prepared for USACE Flood and Coastal Systems Program

US Army Engineer Research and Development Center Coastal and Hydraulics Laboratory

Vicksburg, MS 39180-6199

Under Funding Account Code 39JK18, AMSCO Code 060000 


\section{Abstract}

This technical report presents the new numerical modeling capabilities for simulating wave attenuation and mean water level changes through flexible vegetation such as smooth cordgrass in coastal and marine wetlands. These capabilities were implemented into the Cross-SHORE (CSHORE) numerical model. The biomechanical properties of vegetation such as dimensions, flexibility, and bending strength are parameterized in terms of the scaling law. Correspondingly, a new formulation of the vegetation drag coefficient, $C_{D}$, is developed using field data from a salt marsh in Terrebonne Bay, LA, by considering spatially varying effective stem and blade heights of species. This report also presents a general procedure for using the model to simulate hydrodynamic variables (i.e., waves, currents, mean water levels) at vegetated coasts, which are used to quantify the effects of wave attenuation and reduction of surge and runup due to vegetation. Preliminary model validation was conducted by simulating a set of laboratory experiments on synthetic vegetation, which mimicked the flexibility of Spartina alterniflora. The validation results indicate that the newly developed vegetation capabilities enable CSHORE to predict changes of wave heights and water levels through marshes by considering species-specific biomechanical features. The model is also applicable to assess vegetation effectiveness against waves and surges.

DISCLAIMER: The contents of this report are not to be used for advertising, publication, or promotional purposes. Citation of trade names does not constitute an official endorsement or approval of the use of such commercial products. All product names and trademarks cited are the property of their respective owners. The findings of this report are not to be construed as an official Department of the Army position unless so designated by other authorized documents. 


\section{Contents}

Abstract................................................................................................................ ii

Figures and Tables.............................................................................................iv

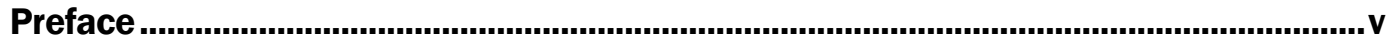

1 Introduction ................................................................................................................ 1

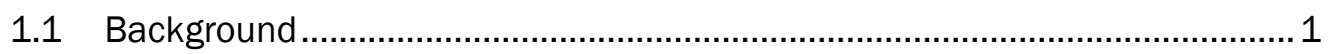

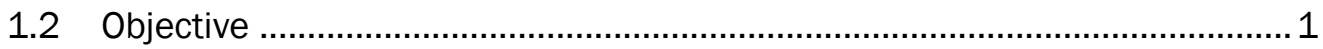

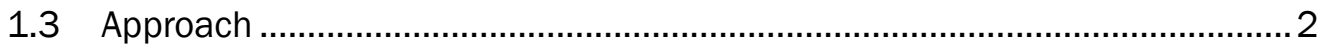

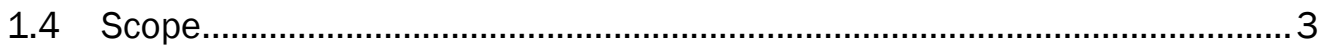

2 Mathematical Formulations for Modeling Wave Attenuation due to Vegetation by CSHORE-Vegetation............................................................................... 4

3 Modeling Resistance of Flexible Vegetation against Waves and Currents............. 7

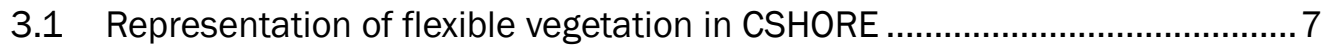

3.2 Determining drag coefficient CD for flexible vegetation.................................9

3.3 Procedure for simulating wave attenuation due to flexible vegetation ....... 12

4 Calibration of CD Using Field Data from Tropical Storm Lee ...............................15

5 Model Validation for Simulation of Wave Attenuation in Laboratory ......................19

6 Conclusions and Recommendations..................................................................24

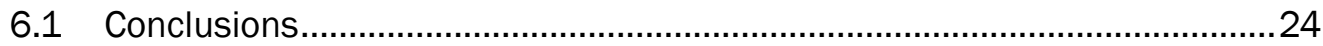

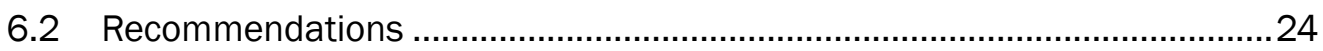

References............................................................................................................................ 26

Appendix: Control Variables of CSHORE-Vegetation for Selecting Model

Capabilities .....................................................................................................................29

Unit Conversion Factors......................................................................................30

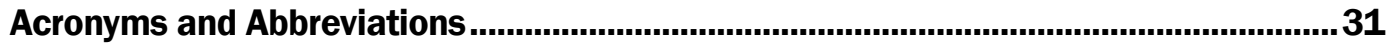

Report Documentation Page 


\section{Figures and Tables}

\section{Figures}

Figure 1. Sketch of wave propagation through vegetation and variables employed in the model

Figure 2. (a) Height variables for vegetation with blades; (b) Ratio of effective stem height to stem height calculated by Equation (7).

Figure 3. Flow chart for determining capacity of living vegetation using CSHORE-Vegetation

Figure 4. Study site at Terrebonne Bay, LA: (a) Close-up aerial view of the study site showing wave gage configuration (the background Google Earth satellite image is dated to 11/14/2012). The line W1-W3 (28 m, drawn to scale) shows transect alignment. (b) A Spartina alterniflora plant collected from the site for measurements. (c) Profile view of the experimental set up. (from Jadhav 2012).

Figure 5. $C_{D}$ vs. Re for CSHORE-Vegetation for Spartina alterniflora. The re-fitted curve was obtained by including ESH and EBH. The curve developed by Jadhav (2012) was using stem height only.

Figure 6. (a)-(f): Comparisons of profiles of wave heights $\left(\mathrm{H}_{r m s}\right)$ through the vegetation patch $(x=0.0 \sim 9.8 \mathrm{~m})$.

Figure 7. Observed vs. computed Hrms at all the gages and for all the 27 experiments. $\left(R^{2}=\right.$ Coefficient of Determination, NRMSD $=$ Normalized RootMean-Square Deviation from the mean observed Hrms).

\section{Tables}

Table 1. Empirical formulations of $\mathrm{CD}$ for rigid and flexible vegetation.

Table 2. Vegetation properties (units, mean, and standard deviation) (Jadhav 2012)

Table 3. Vegetation properties in laboratory experiments by Anderson and Smith (2014)

Table 4. Model parameters.

Table 5. Control variables and optional values for selecting the model vegetation capabilities. 


\section{Preface}

This study was conducted for the US Army Corps of Engineers, Flood and Coastal Systems Program, US Army Engineer Research and Development Center (ERDC), Coastal and Hydraulics Laboratory (CHL), under Funding Account Code 39JK18, AMSCO Code 060000.

The work was performed by the Coastal Processes Branch of the Flood and Storm Protection Division, ERDC-CHL. The general administrative supervision was provided by Ms. Ashley E. Frey, chief, Coastal Processes Branch, and Dr. Cary A. Talbot, chief, Flood and Storm Protection Division. At the time the study was completed, Dr. Julie Dean Rosati was the technical director for Flood and Risk Management; the deputy director of ERDC-CHL was Mr. Jeffrey R. Eckstein; and the director was Dr. Ty V. Wamsley.

At the time of publication of this report, Mr. Keith Flowers was deputy director of CHL, and the director was Dr. Ty V. Wamsley.

Sincere appreciation is expressed to Ms. Margaret B. Owensby and Ms. Sally (Catie) Dillon for their valuable review comments.

The commander of ERDC was COL Teresa A. Schlosser, and the director was Dr. David W. Pittman. 


\section{Introduction}

\subsection{Background}

Vegetation on coasts and in marine wetlands attenuates wave energy, slows water velocity, reduces wave runup, and stabilizes sediments, thereby providing coastal storm protection (e.g., Leonard and Luther 1995; Nepf 1999; Bridges et al. 2015; Smith et al. 2016). Lower-energy wave attenuation effects of vegetation have been recognized for years based on laboratory and field observations, analytical approaches, and numerical modeling (e.g., Dalrymple et al. 1984; Kobayashi et al. 1993; BaronHyppolite et al. 2019). During high-energy events such as tropical storms and cold fronts, high waves and strong currents on high water levels can erode sediments and shorelines and lead to a faster marsh deterioration (e.g., Leonardi et al. 2018; Bendoni et al. 2019). The repeated bending of vegetation due to wave action may lead to broken stems and damaged marshes, dependent on species-specific flexibility (e.g., Rupprecht et al. 2017). However, most existing numerical models for wave attenuation (e.g., SWAN [2020]; XBEACH [2020]) employ simplified empirical vegetation models that were developed for rigid vegetation based on linear wave theory. Therefore, those models are inadequate to simulate hydrodynamic and morphodynamic responses of salt marshes to waves and surges due to varying biomechanical features.

To quantify storm conditions that make vegetation ineffective or permanently damaged, it is imperative to determine how vegetation biogeomechanical features (heights, drag resistance, flexibility, rigidity, bending, and breakage) change with conditions of waves and water levels (surges). The thresholds dependent on wave forcing and those properties of vegetation are key parameters to assess resilience of vegetated coasts against flood risks within dynamic environmental conditions. Therefore, to assess vegetation effects on flood risk reduction and erosion protection, a systematic evaluation methodology or procedure to predict varying capacity of flexible vegetation (e.g., salt marshes) with time and location is needed.

\subsection{Objective}

The objective of this study is to develop a numerical model and a general simulation procedure to compute wave attenuation and mean water level (MWL) changes through vegetated coasts and marshes by considering 
biomechanical features of marshes such as density, sizes, and flexibility. The numerical model for assessment of vegetation effect was developed based on an existing one-dimensional (1-D) coastal profile evolution model. The procedure aims to guide users to using the model for calculation of wave attenuation and drag resistance due to varying flexibility of different species (cordgrasses) on dynamic wave conditions. Thus, the numerical model results can be utilized for evaluating performance of different types of vegetation for flood protection in vegetated coasts and wetlands.

\subsection{Approach}

For the purpose, the Cross-SHORE Numerical Model (CSHORE) (Johnson et al. 2012), a 1-D cross-shore coastal processes model, was selected as a base model to further develop specific capabilities for simulating wave attenuation, currents, and MWLs (including setup and runup) in vegetated coasts and marine wetlands. Through implementation of those vegetation capabilities into CSHORE, an extension version of this model, named the CSHORE-Vegetation model, has been developed.

For simulation of wave attenuation, the CSHORE-Vegetation model provides two formulations to calculate the energy dissipation due to vegetation. The first formulation is the frequency-independent formulation based on the Rayleigh distribution of random waves proposed by Mendez and Losada (2004). The other is a frequency-dependent energy dissipation formulation developed by Chen and Zhao (2012) based on the measured or a Joint North Sea Wave Project (JONSWAP) spectrum (Hasselmann et al. 1980). The model capabilities for rigid vegetation have been successfully validated by comparing cross-shore profiles of wave heights and MWLs with laboratory experiments (Chen et al. 2017, 2019; Zhu et al. 2019; Ding et al. 2019a,b) and field cases (Chen et al. 2019).

To simulate the hydrodynamic effects of vegetation on waves, a phaseaveraged and depth-integrated drag force was added into the momentum equation to model vegetation resistance against propagation of waves and mean currents (Chen et al. 2017, 2019; Zhu et al. 2019). The drag force consists of a Morison-type drag force due to pure wave action and a force against mean currents such as undertow. To simulate the effect of nonlinear wave dynamics on vegetation resistance (Dean and Bender 2006), a novel drag forcing formulation based on nonlinear wave shape models (using the finite-amplitude wave theory to produce skewed and 
non-sinusoidal waves) was developed and verified for both submerged and emergent vegetation (Zhu et al. 2019; Zhu and Chen 2019). Meanwhile, Zhu and Chen (2019) have developed a method to use a consistent drag coefficient for calculating wave energy dissipation and drag resistance by using stream-function wave theory.

For modeling aquatic vegetation resistance against waves and currents, the scaling law (Lei and Nepf 2019) is used to estimate the effective vegetation heights in stem and blades by considering vegetation bending and flexibility against wave actions. To provide a general formulation for calculating wave energy dissipation and vegetal drag force due to different types of vegetation, a unified $C_{D}$ formulation was developed based on field data of vegetation and wave data, obtained at Terrebonne Bay, LA. Validation of the CSHORE-Vegetation model with the unified drag coefficient formulation was conducted by simulating a set of laboratory experiments on flexible/synthetic vegetation (Anderson and Smith 2014), which mimicked the flexibility of Spartina alterniflora.

\subsection{Scope}

This technical report highlights the recent development of simulation capabilities with regards to wave attenuation caused by flexible vegetation in CSHORE-Vegetation. The following sections give (1) a brief description of the mathematical equations of CSHORE-Vegetation, (2) calculations of biomechanical properties of flexible vegetation in terms of the scaling law, (3) determination of the drag coefficient for calculating wave energy loss and drag forcing of flexible vegetation, (4) a procedure for using CSHOREVegetation to simulate wave attenuation by considering biomechanical features of plants, (5) development of a unified drag coefficient formulation using field data, (6) model validation using results from the simulation of wave attenuation in a US Army Engineer Research and Development Center (ERDC), Coastal and Hydraulics Laboratory (CHL), experimental flume, and finally, (7) conclusions based on this work. 


\section{Mathematical Formulations for Modeling Wave Attenuation due to Vegetation by CSHORE-Vegetation}

This chapter presents a brief description of mathematical formulations for implementing vegetation simulation capabilities into the CSHORE model (Johnson et al. 2012). The implementation enables this model, CSHOREVegetation, to simulate wave attenuation and changes of mean water elevations due to vegetation resistance against waves and currents.

The original CSHORE model simulates phase-averaged wave processes, mean currents, sediment transport, and beach profile morphological changes, under the assumption of the so-called alongshore uniformity which is characterized by alongshore uniform bathymetry (i.e., with regular shore-parallel contours) and currents. For phase-averaged hydrodynamics, CSHORE solves a 1-D cross-shore steady wave energy balance equation and a steady cross-shore momentum equation. As the capability of modeling sediment transport and morphological change is beyond the scope of this study, only the mathematical formulations for conservation of wave energy and momentum are briefly described below.

The 1-D steady wave energy $(E)$ balance equation of CSHORE-Vegetation includes energy damping due to breaking, bottom friction, and newly implemented vegetal energy loss:

$$
\frac{\partial}{\partial x}\left[\frac{E}{\sigma}\left(C_{g}+\frac{Q_{x}}{h}\right)\right]=-\frac{D_{B}+D_{f}+D_{v}}{\sigma}
$$

where $x=$ the cross-shore coordinate, $\sigma=$ angular frequency, $C_{g}=$ group velocity, $h=$ total water depth (from bottom to water surface), $Q_{x}=$ crossshore volume flux, $D_{B}=$ energy loss due to wave breaking, $D_{f}=$ energy loss due to bottom friction, $D_{v}=$ energy dissipation due to vegetation resistance. CSHORE also includes the roller effect of breaking. The detailed definitions and formulations of $D_{B}$ and $D_{f}$ can be found in Johnson et al. (2012).

The CSHORE-Vegetation model provides two options for calculating the energy dissipation due to vegetation. The first is the formulation of Mendez and Losada (2004), in which the irregular waves are based on the 
Rayleigh distribution, and the energy attenuation is independent of frequency:

$$
D_{v}=\sigma Q_{v}=\frac{1}{2 \sqrt{\pi}} \rho C_{D} b_{v} N_{v}\left(\frac{k g}{2 \sigma}\right)^{3} \frac{\sinh ^{3}\left(k h_{v}\right)+3 \sinh \left(k h_{v}\right)}{3 k \cosh ^{3}(k h)} H_{r m s}^{3}
$$

where $\rho=$ water density $\left(\mathrm{kg} / \mathrm{m}^{3}\right)^{*}, C_{D}=$ non-dimensional vegetal drag coefficient for random waves, $b v=$ the plant area per unit height of each vegetation stand normal to horizontal velocity (m), $N_{v}=$ number of vegetation stands per unit horizontal area $\left(\mathrm{m}^{-2}\right), k=$ wave number, $g=$ the gravitational acceleration $\left(\mathrm{m} / \mathrm{s}^{2}\right), h_{v}=$ vegetation height $(\mathrm{m}), H_{r m s}=$ rootmean-square wave height (m). Another $D v$ formulation for frequencydistributed wave attenuation has been developed by Chen and Zhao (2012), which uses the measured or a JONSWAP spectrum for irregular waves.

The 1-D momentum equation of CSHORE-Vegetation for calculating the steady mean water surface elevation (MWSE) profile in the cross-shore direction is modified by Zhu et al. (2019) as follows:

$$
\rho g h \frac{\partial \eta}{\partial x}=-\frac{\partial}{\partial x}\left[S_{x x}+\rho \frac{Q_{x}^{2}}{h}\right]+\tau_{s x}-\tau_{b x}+F_{v}+F_{v, m}
$$

where $\eta$ is the MWSE above the still water level (SWL), $S_{x x}=$ cross-shore radiation stress (roller effect included), $\tau_{s x}=$ surface shear stress due to wind, $\tau_{b x}=$ averaged bottom shear stress, $F_{v, m}=$ the drag force of vegetation against the mean current (e.g. undertow, tidal currents), and $F_{v}$ is the Morison-type drag force on water column by vegetation stems:

$$
F_{v}=\frac{1}{T} \int_{t}^{t+T} \int_{Z_{b}}^{\min \left(-h+h_{v}, \eta\right)} \frac{1}{2} \rho C_{D} b_{v} N_{v}|u| u d z d t
$$

where $t=$ time, $T=$ wave period, $Z_{b}=$ bed elevation relative to the SWL, and $u=u(z, t)$, the horizontal particle velocity of wave. The forces acting on the water column on a sloping beach with vegetation are illustrated in

\footnotetext{
* For a full list of the spelled-out forms of the units of measure used in this document, please refer to US Government Publishing Office Style Manual, 31st ed. (Washington, DC: US Government Publishing Office 2016), 248-52, https://www.govinfo.gov/content/pkg/GPO-STYLEMANUAL-2016/pdf/GPOSTYLEMANUAL-2016.pdf.
} 
Figure 1. Note that the mean (phase- and depth-averaged) velocity is calculated by the total volume flux, consisting of the cross-shore volume flux $Q_{x}$, the roller flux, and the flux caused by linear wave propagation (Johnson et al. 2012, Equation 42).

Figure 1. Sketch of wave propagation through vegetation and variables employed in the model

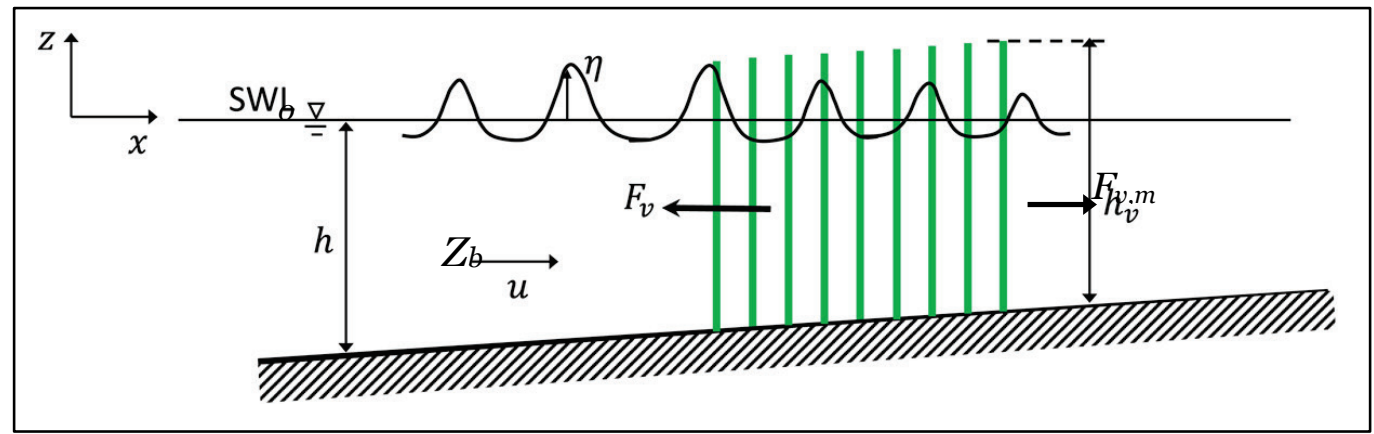

Note that $F_{v}$ in Equation (4), if integrated from bottom to SWL, becomes zero if using the symmetrical horizontal particle velocities $u$ from linear wave theory; this is not realistic for waves in shallow water and may miscalculate the vegetal drag forcing (Dean and Bender 2006). For CSHORE-vegetation, Zhu and Chen (2019) developed a semi-analytical formulation to calculate the drag force caused by random waves acting on submerged or emergent vegetation using the stream-function wave theory:

$$
F_{v}=\frac{1}{16 \sqrt{\pi}} \rho C_{D} b_{v} N_{v} \bar{\omega}^{2} H_{r m s}^{3} \frac{\cosh ^{2} \bar{k} h_{v}}{\sinh ^{2} \bar{k} h_{v}} f_{\alpha}
$$

where $H_{r m s}=$ the root-mean-square wave height, $\bar{\omega}=$ the wave angular frequency corresponding to the mean period, and $\bar{k}=$ the wave number associated with $\bar{\omega} . f_{\alpha}$ is the correction factor that is dependent on vegetation submergence and local wave parameters (wave height, period, and water depth). Zhu and Chen (2019) have provided a comprehensive database of $f_{\alpha}$ values by calculating the values of this factor in advance for a total of 6,066 waves, which cover a wide range of wave conditions from deep to shallow water. 


\section{Modeling Resistance of Flexible Vegetation against Waves and Currents}

This chapter presents a mathematical model to calculate resistance of flexible vegetation by means of the scaling law, which considers interaction of vegetation biomechanical features and waves. A brief literature review on the existing formulations of drag coefficient of vegetation is provided. A formulation applicable to a wide range of biomechanical parameters is recommended. Then, a general procedure for determining the drag resistance of flexible vegetation in CSHOREVegetation is presented.

\subsection{Representation of flexible vegetation in CSHORE}

Vegetation on coasts and in marshes resists forcing from waves, currents, and wind, and reacts to the influence of these natural forces by bending and swaying. However, if the natural forces acting on vegetation exceed its flexural stress (the limit of recovery capability from bending), vegetation will be partially damaged, or its stem will be broken.

The motion of flexible vegetation leads to smaller relative velocities $u_{r}$ (which is equal to $u-u_{v}$ ) than the orbital velocity $u$, where $u_{v}$ is the stem swaying velocity. The smaller relative velocities reduce the vegetationinduced drag force and the associated energy dissipation. To account for the effects of vegetation flexibility and motion on wave attenuation, the concept of effective vegetation height $h_{e}$ is employed (Lei and Nepf 2019). The essential idea is that rigid vegetation with an effective vegetation height $\left(h_{e}\right)$ dissipates the equivalent amount of wave energy as flexible vegetation with the height of $h_{v}$. For vegetation with blades (Figure 2a), wave energy is attenuated by stem and blades, and the total effective vegetation height $\left(h_{v t, e}\right)$ then consists of the effective stem height $\left(h_{s t e m, e}\right)$ and the sum of all the effective individual blade heights $\left(h_{\text {blade, }, e}\right)$ :

$$
h_{v t, e}=h_{\text {stem }, e}+\sum_{i}^{n} h_{\text {blade }, i, e}
$$

where $n$ is the total number of blades and the subscript $i$ indicates the $i$-th individual blade. For determining the effective stem height, the following scaling law (Lei and Nepf 2019) is used:

$$
h_{\text {stem }, e}=0.94(\mathrm{CaL})_{\text {stem }}^{-1 / 4} h_{v}
$$


where $C a$ is the wave Cauchy number, $L$ is the length ratio between plant height $\left(h_{v}\right)$ and maximum water particle displacement or wave orbital excursion $\left(A_{w}\right)$, and the subscript "stem" indicates that $C a$ and $L$ are evaluated for the stem. The definitions of the two variables are given as follows:

$$
C a=\frac{\rho b_{v} U_{w}^{2} h_{v}^{3}}{E I}
$$

where $U_{w}$ is a representative horizontal velocity, defined as the depthaveraged (wave) orbital velocity immediately in the front of the vegetation field, $E$ is the Young's modulus, and $I\left(=\frac{\pi b_{v}^{4}}{64}\right)$ is the area moment of inertia for a circular cross-section of stem.

$$
L=\frac{h_{v}}{A_{w}}=\frac{2 \pi h_{v}}{U_{w} T}
$$

where $A_{w}=\frac{U_{w} T}{2 \pi}$, and $T$ is the wave period. Figure 2(b) plots the curve of the ratio of effective stem height to stem height $\left(h_{e} / h_{v}\right)$ calculated by Equation (7). The term $C a L$ is a ratio of drag force to vegetation stiffness. A larger $C a L$ value means the vegetation becomes more flexible against the wave, then the effective vegetation height becomes less or shorter. Note that for most flexible vegetation, the effective height should be equal to or shorter than the actual height, as the ratio $\left(h_{e} / h_{v}\right)$ greater than 1 may not be physical.

Similarly, the scaling law is applied to calculate the effective height (or length) of the $i$-th individual blade:

$$
h_{\text {blade }, i, e}=0.94(C a L)_{b l a d e, i}^{-1 / 4} h_{b, i}
$$

where the subscript "blade" indicates that the two variables $C a$ and $L$ are evaluated for the blades, and $h_{b, i}$ is the height (or length) of the $i$-th blade.

When the CSHORE-Vegetation model calculates the energy dissipation $D_{v}$ due to flexible vegetation, the vegetation height $h_{v}$ in Equation (2) will be replaced by the total effective vegetation height $h_{v t, e}$. Similarly, for calculation of the vegetal drag force by Equation (5) in the momentum equation, the total effective vegetation height will be used. 
Figure 2. (a) Height variables for vegetation with blades; (b) Ratio of effective stem height to stem height calculated by Equation (7).
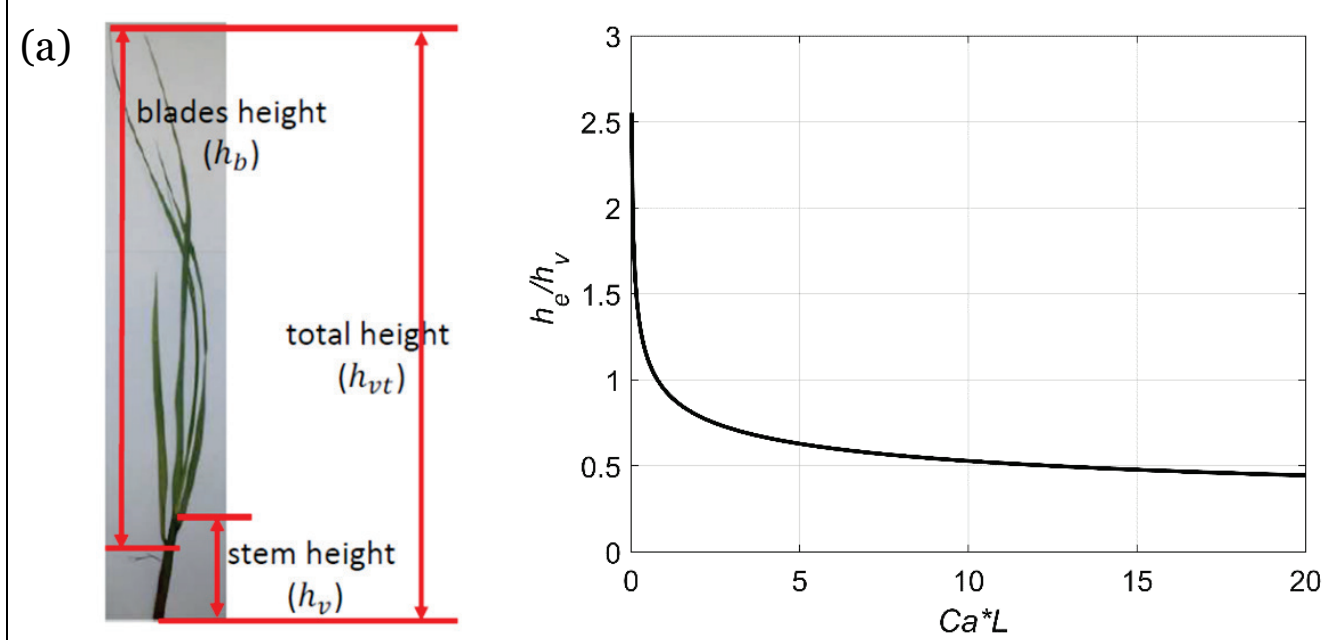

(b)

\subsection{Determining drag coefficient $C_{D}$ for flexible vegetation}

The drag coefficient $C_{D}$ is an empirical parameter for calculating wave energy loss and drag resistance of vegetation against waves and currents. The $C_{D}$ values can be calibrated based on a wave attenuation model by using observation data measured in laboratories and field studies. Therefore, $C_{D}$ represents the bulk value over a measured transect or a vegetation patch rather than the drag coefficient of a single cylinder-like vegetation stem. For prediction purposes, there were a number of empirical formulations developed for estimating $C_{D}$ by building up a regression relationship between $C_{D}$ and wave parameters from the calibrated values. The applications of those empirical $C_{D}$ formulations are limited by the type of vegetation (rigid/flexible), the wave properties (regular/irregular), the data range, and the wave models (analytical or process-based models) used for calibrating the bulk values.

Pioneering research by Dalrymple et al. (1984) derived an analytical solution of wave height decay due to arrays of cylinders (a rigid vegetation patch) from the linear wave theory for monochromatic (regular) waves. Kobayashi et al. (1993) developed a wave energy balance equation for submerged rigid vegetation and established a regression relationship between $C_{D}$ and the Reynolds number (Re) for non-breaking regular waves, where

$$
R e=\frac{u_{c} b_{v}}{v}
$$


where $u_{c}$ is the maximum near-bed orbital velocity in the absence of vegetation and $v$ is the kinematic viscosity of water. Mendez and Losada (2004) extended the study to wave attenuation due to breaking irregular waves and derived two analytical solutions of wave height profiles in a horizontal vegetated flume: one for non-breaking waves and another for breaking irregular waves. Under random wave conditions, they developed an empirical $C_{D}$ formulation for rigid vegetation related to the KeuleganCarpenter number $\left(K_{C}\right)$ :

$$
K_{C}=\frac{u_{c} T_{p}}{b_{v}}
$$

where $u_{c}$ is defined as the maximum horizontal velocity at the middle of the vegetation field at the canopy and $T_{p}$ is the peak wave period.

Based on the analytical solution of Mendez and Losada (2004) for random waves, Jadhav (2012) calibrated the $C_{D}$ values for Spartina alterniflora using field data from Terrebonne Bay, LA, and found a regression relation for $C_{D}$ with the Reynolds number (Re). Anderson and Smith (2014) conducted a large number of experiments for studying wave attenuation in the ERDC CHL, wave flume in which the vegetation mimicked the flexibility of Spartina alterniflora. Using their non-breaking wave data, they developed four $C_{D}$ formulations related to the Reynolds number or the Keulegan-Carpenter number $\left(K_{C}\right)$ and found the $C_{D}$ curve related to a modified Re value provided the best fit with their laboratory datasets. All the above-mentioned $C_{D}$ formulations are limited to rigid vegetation, due to a lack of representation of vegetation flexibility.

Finally, applying the scaling law to Spartina alterniflora as described in the previous section, Zhu et al. ${ }^{*}$ have developed a new $C_{D} \sim R e$ formulation for Spartina alterniflora based on the field data from Terrebonne Bay and the calibrated $C_{D}$ values produced by the CSHORE-Vegetation model. It was also successfully validated by simulating the wave attenuation experiments by Anderson and Smith (2014). More information on the calibration of $C_{D}$ and validation of this formulation is given in the next sections.

\footnotetext{
* Zhu, L., Q. Chen, Y. Ding, J. Navid, H. Q. Wang, B. Johnson, and J. D. Rosati. In preparation. "Universal Relation of Drag Coefficient for Quantifying Wave Energy Reduction by Salt Marshes." Submitted to PNAS, Aug. 2020.
} 
Table 1 provides more detailed information on the above-mentioned five $C_{D}$ formulations. It includes wave data conditions, vegetation properties, the models used for developing the formulations, and limitations for application. All five curves are linked to Re or $K_{C}$, and each one uses a specific definition of $u_{c}$. As the drag coefficient is in inverse proportion to both $K_{C}$ or $R e$, the resistance of a species is decreased as wave height or energy increases. The limitation of each $C_{D}$ formulation is indicated in the table by the type of vegetation (rigid or flexible) and the application ranges of the parameters $\left(C_{D}, R e\right.$, and $\left.K_{C}\right)$.

In Table 1, except for the field data of Spartina alterniflora measured in Terrebonne Bay, LA, during Tropical Storm Lee in 2011, all of the other laboratory data sets (Kobayashi et al 1993; Dubi 1995; Anderson and Smith 2014) were measured in wave flumes using artificial vegetation to mimic real vegetation in the field. However, the $C_{D}$ formulae by Mendez and Losada (2004) (Equation 14), Jadhav (2012) (Equation 15), Jadhav et al. (2013) (Equation 16), and Anderson and Smith (2014) (Equation 17) were developed for rigid vegetation without considering the flexibility of vegetation. Only the $C_{D}$ formulation Equation (18) by Zhu et al. ${ }^{*}$ was developed by using the scaling law and the process-based model CSHOREVegetation. It therefore is able to quantify the effects of vegetation flexibility, rigidity, and bending stress.

Table 1. Empirical formulations of $C_{D}$ for rigid and flexible vegetation.

\begin{tabular}{|c|c|c|c|c|}
\hline Study & Wave Conditions & Vegetation & $\begin{array}{l}\text { Model for Rigid } \\
\text { or Flexible } \\
\text { Vegetation }\end{array}$ & $C_{D}$ Formulation \\
\hline $\begin{array}{l}\text { Kobayashi } \\
\text { et al. } \\
(1993)\end{array}$ & $\begin{array}{l}\text { Monochromatic } \\
\text { Waves: } \\
h=0.45-0.52 \mathrm{~m} \\
H_{0}=0.036-0.194 \mathrm{~m} \\
\mathrm{~T}=0.71-2.0 \mathrm{~s}\end{array}$ & $\begin{array}{l}\text { Artificial kelp } \\
h_{v}=25 \mathrm{~cm} \\
b_{v}=5.2 \mathrm{~cm} \\
t=0.03 \mathrm{~mm} \\
N_{v}=1100 \text { and } \\
1490 / \mathrm{m}^{2}\end{array}$ & $\begin{array}{l}\text { Analytical } \\
\text { solution for non- } \\
\text { breaking regular } \\
\text { waves over a flat } \\
\text { bed (rigid) }\end{array}$ & $\begin{array}{l}C_{D}=\left(\frac{2200}{R e}\right)^{2.4}+0.08(13) \\
2,200<R e<18,000, \\
0.08<C_{D}<1.08 \\
u_{c} \text { for } R e: \text { Maximum near-bed } \\
\text { orbital velocity of } H_{0}\end{array}$ \\
\hline $\begin{array}{l}\text { Mendez } \\
\text { and } \\
\text { Losada } \\
(2004)\end{array}$ & $\begin{array}{l}\text { Wave flume (Dubi } \\
\text { 1995): } \\
h=0.40-1.00 \mathrm{~m} \\
H_{r m s}=0.045-0.17 \mathrm{~m} \\
T_{p}=1.26-4.42 \mathrm{~s}\end{array}$ & $\begin{array}{l}\text { Artificial kelp } \\
h_{v}=20 \mathrm{~cm} \\
b_{v}=2.5 \mathrm{~cm} \\
N_{v}=1200 / \mathrm{m}^{2}\end{array}$ & $\begin{array}{l}\text { Analytical } \\
\text { solution for non- } \\
\text { breaking } \\
\text { irregular waves } \\
\text { over a flat bed } \\
\text { (rigid) }\end{array}$ & $\begin{array}{l}C_{D}=Q^{-0.3} e^{-0.0138 Q}(14) \\
Q=\frac{K_{C}}{\alpha^{0.76}}, \alpha=h_{v} / h \\
7 \leq Q \leq 172\end{array}$ \\
\hline
\end{tabular}

* Zhu, L., Q. Chen, Y. Ding, J. Navid, H. Q. Wang, B. Johnson, and J. D. Rosati. In preparation. "Universal Relation of Drag Coefficient for Quantifying Wave Energy Reduction by Salt Marshes." Submitted to PNAS, Aug. 2020. 


\begin{tabular}{|c|c|c|c|c|}
\hline Study & Wave Conditions & Vegetation & $\begin{array}{l}\text { Model for Rigid } \\
\text { or Flexible } \\
\text { Vegetation }\end{array}$ & $C_{D}$ Formulation \\
\hline & & & & $\begin{array}{l}u_{c} \text { for } K_{C} \text { : Maximum orbital } \\
\text { velocity at the middle of the } \\
\text { vegetation field at canopy }\end{array}$ \\
\hline $\begin{array}{l}\text { Jadhav } \\
\text { (2012) }\end{array}$ & $\begin{array}{l}\text { Waves measured in } \\
\text { Terrebonne Bay, LA } \\
h=0.20-1.10 \mathrm{~m} \\
H_{m 0}=0.20-0.40 \mathrm{~m} \\
\text { Mean period } \bar{T}=3-9 \mathrm{~s}\end{array}$ & $\begin{array}{l}\text { Spartina } \\
\text { alterniflora } \\
h_{v}=20 \mathrm{~cm} \\
b_{v}=8.5 \mathrm{~mm} \\
N_{v}=420 / \mathrm{m}^{2}\end{array}$ & $\begin{array}{l}\text { Analytical } \\
\text { solution for } \\
\text { breaking } \\
\text { irregular waves } \\
\text { over a flat bed } \\
\text { (Mendez and } \\
\text { Losada 2004) } \\
\text { (rigid) }\end{array}$ & $\begin{array}{l}C_{D}=0.36+\frac{2600}{R e}(15) \\
600 \leq R e \leq 3,200 \\
1.1<C_{D}<4.7 \\
u_{c} \text { for Re: the same definition } \\
\text { as Kobayashi et al. (1993) }\end{array}$ \\
\hline $\begin{array}{l}\text { Jadhav et } \\
\text { al. (2013) }\end{array}$ & Same as above & Same as above & $\begin{array}{l}\text { Same as above } \\
\text { (rigid) }\end{array}$ & $\begin{array}{l}C_{D}=70 K_{c}^{-0.86}(16) \\
25<K_{c}<135 \\
1.0<C_{D}<4.4 \\
u_{c} \text { for } K_{C} \text { : the same definition } \\
\text { as Kobayashi et al. (1993) }\end{array}$ \\
\hline $\begin{array}{l}\text { Anderson } \\
\text { and Smith } \\
(2014)\end{array}$ & $\begin{array}{l}\text { Waves Flume: } \\
h=0.31-0.53 \mathrm{~m} \\
H_{m 0}=0.05-0.19 \mathrm{~m} \\
T_{p}=1.25-2.25 \mathrm{~s}\end{array}$ & $\begin{array}{l}\text { Polyolefin tube } \\
h_{v}=41.5 \mathrm{~cm} \\
b_{v}=6.4 \mathrm{~mm} \\
N_{v}=200 \\
400 / \mathrm{m}^{2}\end{array}$ & $\begin{array}{l}\text { Same as above } \\
\text { (rigid) }\end{array}$ & $\begin{array}{l}C_{D}=0.11+\left(\frac{2067.7}{R e / \alpha^{1.5}}\right)^{0.64} \\
500<R e<2,500, \\
1.0<C_{D}<2.4 \\
u_{c} \text { for Re: Maximum } \\
\text { horizontal velocity } \\
\text { immediately in the front of } \\
\text { the vegetation field at the top } \\
\text { of the stems }\end{array}$ \\
\hline $\begin{array}{l}\text { Zhu et } \\
\text { al. }{ }^{*}\end{array}$ & $\begin{array}{l}\text { Waves measured in } \\
\text { Terrebonne Bay, LA } \\
\text { (Jadhav 2012). }\end{array}$ & $\begin{array}{l}\text { Spartina } \\
\text { alterniflora } \\
\text { Blade: } E=500 \\
\text { KPa } \\
\text { Stem: } E=80 \mathrm{MPa}\end{array}$ & $\begin{array}{l}\text { CSHORE- } \\
\text { Vegetation } \\
\text { (rigid / flexible) } \\
\text { using the scaling } \\
\text { law }\end{array}$ & $\begin{array}{l}C_{D}=0.62+\left(\frac{1492}{R e}\right)^{1.15} \\
300<R e<6,000 \\
0.8<C_{D}<7.0 \\
u_{c} \text { for Re: the same definition } \\
\text { as Kobayashi et al. (1993) }\end{array}$ \\
\hline
\end{tabular}

\subsection{Procedure for simulating wave attenuation due to flexible vegetation}

A general procedure for using the CSHORE-Vegetation model for simulating waves and water levels through a flexible vegetation zone (patch) includes the following major steps:

\footnotetext{
* Zhu, L., Q. Chen, Y. Ding, J. Navid, H. Q. Wang, B. Johnson, and J. D. Rosati. In preparation. “Universal Relation of Drag Coefficient for Quantifying Wave Energy Reduction by Salt Marshes." Submitted to PNAS, Aug. 2020.
} 
1. For configuration of a CSHORE-Vegetation simulation model, data collection is essential to represent vegetation biomechanical properties for stems and blades (e.g., type of species, population density, height, diameter, thickness, Young's modulus, flexural stresses), morphology (bed elevations, sediments), hydrodynamic forcing (waves, currents, tide levels), and winds. The stem flexural strength is an input parameter defined by the user to check the vegetation's state of bending or breakage (i.e., being ineffective).

2. For quantifying flexibility or rigidity, the scaling law is applied to calculate spatially varying or uniform effective heights of stem and blades (Equations 6-10) based on the vegetation biomechanical properties and local wave characteristics.

3. The total effective vegetation height $\left(h_{v t, e}\right)$ from Equation (6) is then used to compute the wave energy reduction $D v$ and the drag resistance $F_{v}$ (Equation 5) caused by the deformable vegetation. The empirical formulation (Equation 18 in Table 1) is recommended for estimating the bulk $C_{D}$ value for each vegetaton patch. For a given incident wave condition, flexible vegetation may lead to a significant reduction of wave damping capability compared to rigid vegetation, and CSHOREVegetation quantifies such a reduction.

4. Near the marsh edge where the wave height is typically large, if the bending stress exerted by waves on the vegetation exceeds the stem flexural strength, the vegetation breaks, and the affected stems are removed from CSHORE automatically.

A flowchart for the procedure proposed above to apply CSHOREVegetation is illustrated in Figure 3. It indicates that simulations may be iterative or time dependent if evaluation of vegetation's response to varying wave conditions, such as bending and breakage, is included. Then, the model will be able to produce time-varying results of wave attenuation and MWLs that can be used for assessing seasonal and storm-related changes of flexible vegetation. 
Figure 3. Flow chart for determining capacity of living vegetation using CSHORE-Vegetation.

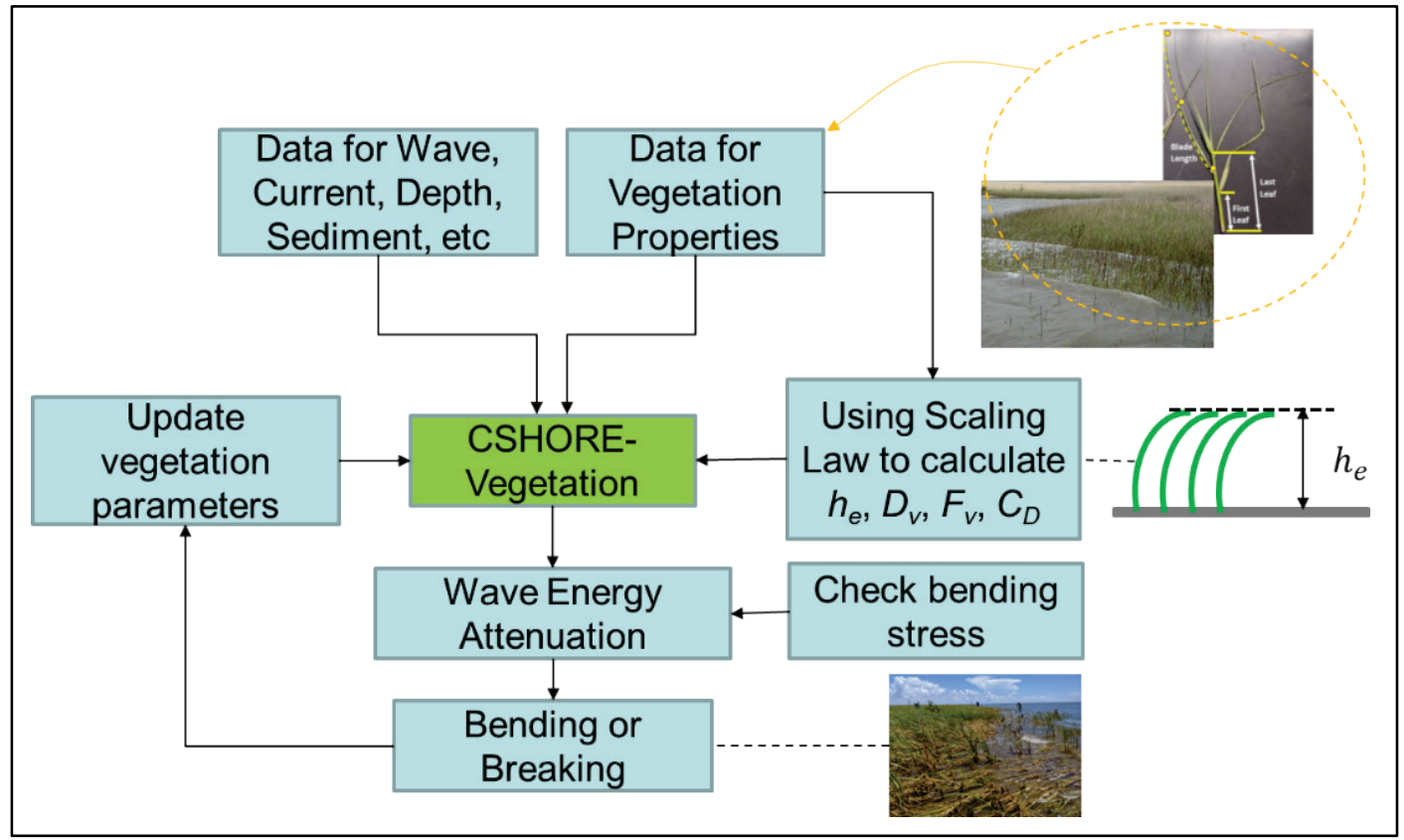




\section{Calibration of $C_{D}$ Using Field Data from Tropical Storm Lee}

The recommended empirical formulation of $C_{D}$ (Equation 18) in Table 1 was developed by means of a regression analysis of the $C_{D}$ values, which were calibrated by using the CSHORE-Vegetation model and field data (for vegetation and waves). The field data were collected by Jadhav and Chen (2012) on 3-4 September 2011 during Tropical Strom Lee (Brown 2011) at Terrebonne Bay on the Louisiana coast (Figure 4). Terrebonne Bay is a shallow estuary where salt marshes line the upper portion of the bay (Figure 4a), including vegetation such as smooth cordgrass (Spartina alterniflora, as shown in Figure 4b) and salt meadow cordgrass (Spartina patens).

This set of field data includes marsh physical properties and wave gage data. Five wave gages (Wo through W4) were deployed along a north-south transect nearly perpendicular to the marsh edge (Figure 4a). Gage Wo was located in the open water on the up-wave side of the marsh approximately $47 \mathrm{~m}$ away from the marsh edge to measure incoming wave energy (Figure 4c). The still water depth relative to the MWL at the location of the gage is approximately $1.4 \mathrm{~m}$. Table 2 summarizes the observed vegetation properties such as density, stem height, total plant height, diameter, modulus, second moment of inertia of the stem, and flexural rigidity ( $E I)$, in the two sections from $\mathrm{W}_{1}$ to $\mathrm{W}_{2}$ and $\mathrm{W}_{2}$ to $\mathrm{W}_{3}$. Vegetation properties are similar in the two sections while the population between W1 and W2 is slightly denser than that in section $\mathrm{W}_{2}-\mathrm{W}_{3}$, and the mean stem height (W1-W2) is approximately $2 \mathrm{~cm}$ shorter than the one in $\mathrm{W}_{2}-\mathrm{W}_{3}$. 
Figure 4. Study site at Terrebonne Bay, LA: (a) Close-up aerial view of the study site showing wave gage configuration (the background Google Earth satellite image is dated to 11/14/2012). The line W1-W3 (28 m, drawn to scale) shows transect alignment. (b) A Spartina alterniflora plant collected from the site for measurements. (c) Profile view of the experimental set up.

(from Jadhav 2012)

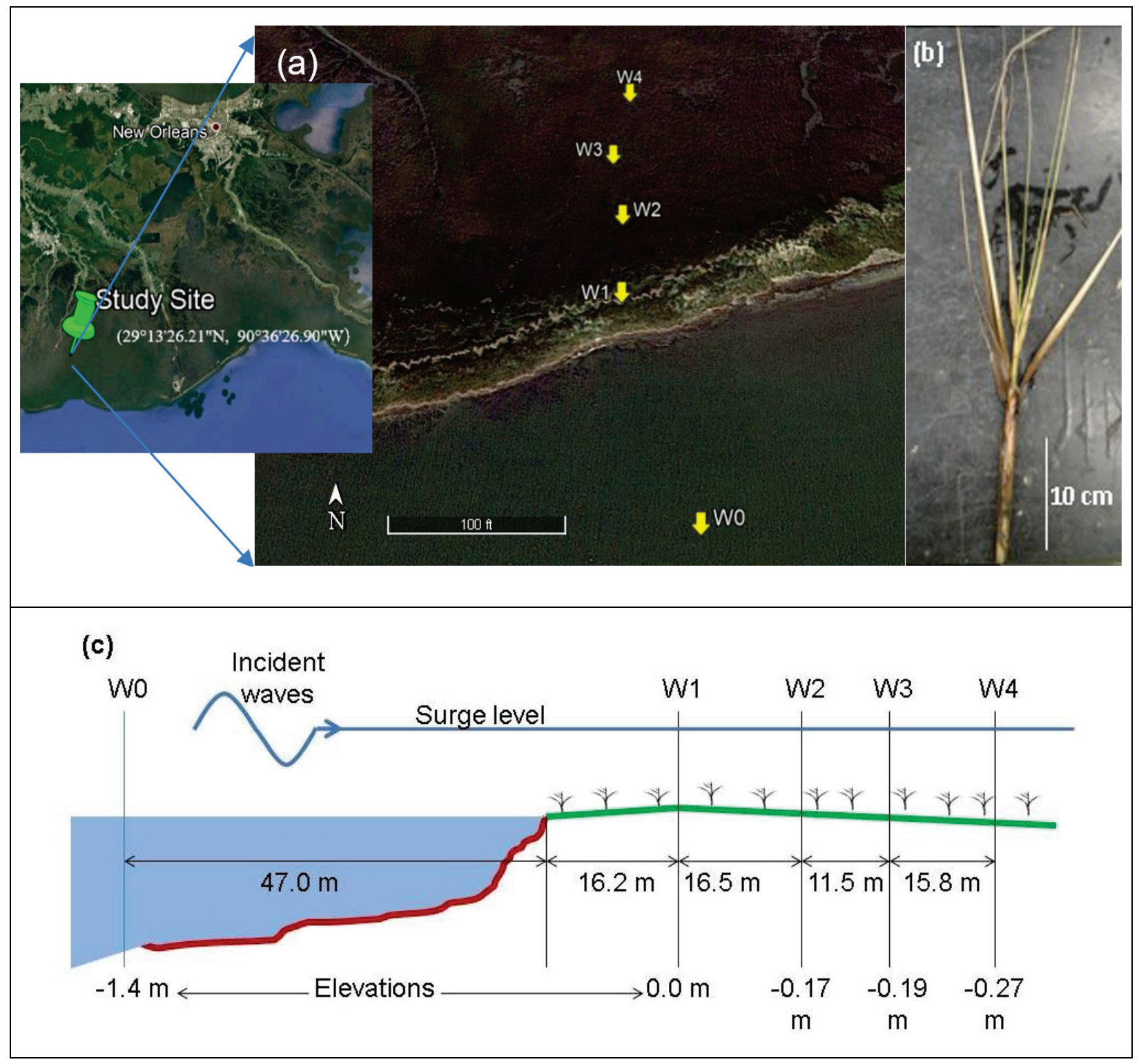


Table 2. Vegetation properties (units, mean, and standard deviation) (Jadhav 2012).

\begin{tabular}{|l|l|l|l|}
\hline Plant parameters & Unit & $\begin{array}{l}\text { Between W1 } \\
\text { and W2 }\end{array}$ & $\begin{array}{l}\text { Between W2 } \\
\text { and W3 }\end{array}$ \\
\hline Population density $\left(N_{v}\right)$ & {$\left[\mathrm{m}^{-2}\right]$} & 424 & 420 \\
\hline Stem height $(h v)$ & {$[\mathrm{m}]$} & $0.21 \pm 0.04$ & $0.23 \pm 0.06$ \\
\hline Total plant height $(h v t)$ & {$[\mathrm{m}]$} & $0.62 \pm 0.05$ & $0.63 \pm 0.11$ \\
\hline Stem diameter $\left(B_{v}\right)$ & {$[\mathrm{mm}]$} & $8.0 \pm 1.1$ & $7.5 \pm 1.3$ \\
\hline Young's modulus $(E)$ & {$[\mathrm{MPa}]$} & $80 \pm 27$ & $79 \pm 32$ \\
\hline Second moment of inertia of stem $(I)$ & {$\left[\mathrm{m}^{4}\right]$} & $2.01 \times 10^{-10}$ & $1.55 \times 10^{-10}$ \\
\hline Flexural rigidity $(E I)$ & {$\left[\mathrm{N}-\mathrm{m}^{2}\right]$} & $0.017 \pm 0.009$ & $0.013 \pm 0.007$ \\
\hline
\end{tabular}

Zhu et al. ${ }^{*}$ applied the CSHORE-vegetation model to calibrate the $C_{D}$ in three sections, Wo-W1, W1-W2, and W2-W3, for which the scaling law was used to estimate the effective stem height (ESH) and the effective blade heights (EBH) of the plants (Spartina alterniflora). The obtained regression relation (the refitted $C_{D} \sim$ Re curve, Eq. 18), plotted in Figure 5, provides a higher accuracy $\left(R^{2}=0.96\right)$ and a wider range of Re for applications than the formulation by Jadhav (2012) (i.e., Equation 15). Note that Jadhav (2012) developed Equation (15) using only the measured stem height without applying the scaling law.

\footnotetext{
* Zhu, L., Q. Chen, Y. Ding, J. Navid, H. Q. Wang, B. Johnson, and J. D. Rosati. In preparation. "Universal Relation of Drag Coefficient for Quantifying Wave Energy Reduction by Salt Marshes." Submitted to PNAS, Aug. 2020.
} 
Figure 5. $C_{D}$ vs. Re for CSHORE-Vegetation for Spartina alterniflora. The re-fitted curve was obtained by including ESH and EBH. * The curve developed by Jadhav (2012) was using stem height only.

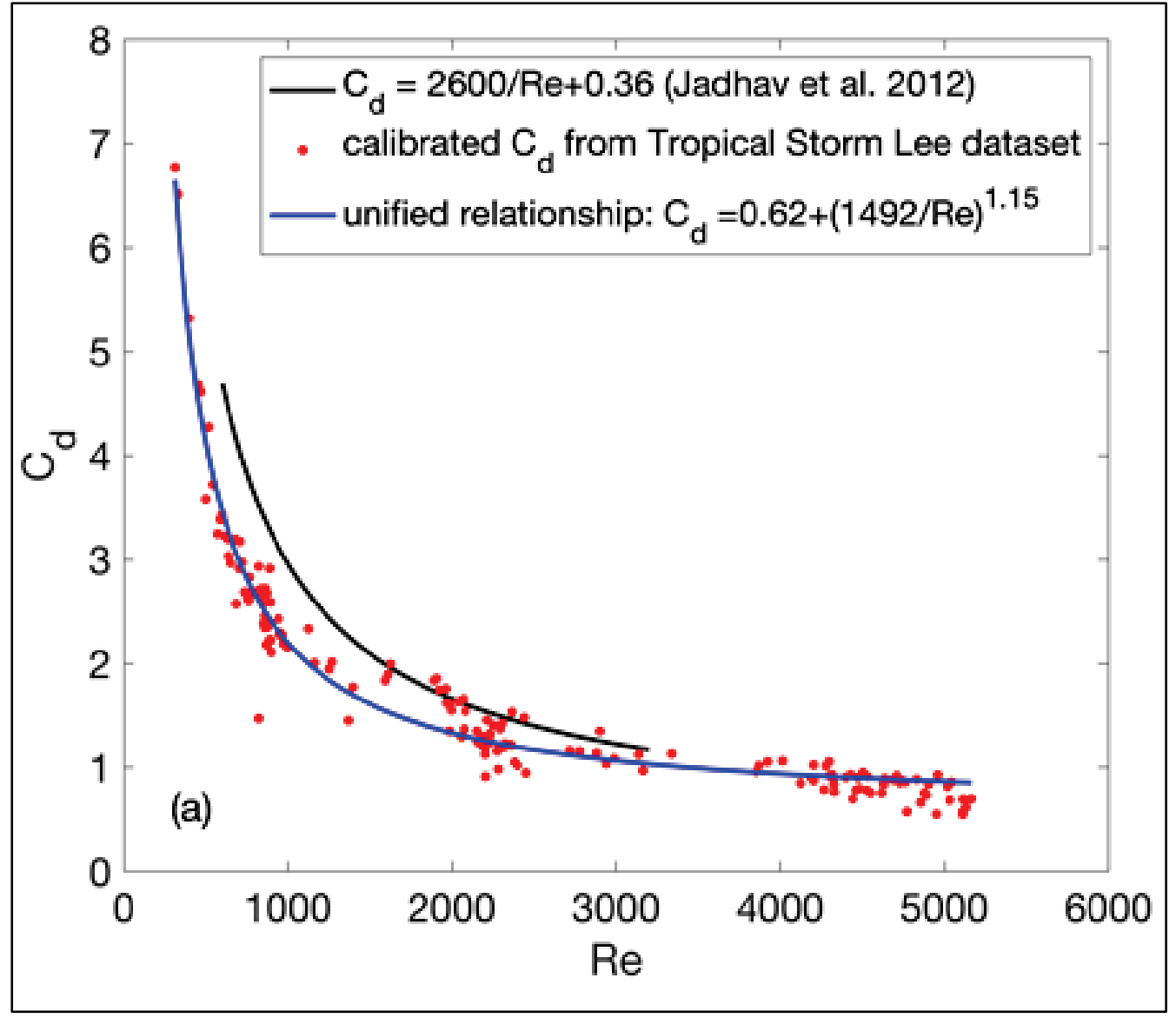

* Zhu, L., Q. Chen, Y. Ding, J. Navid, H. Q. Wang, B. Johnson, and J. D. Rosati. In preparation. “Universal Relation of Drag Coefficient for Quantifying Wave Energy Reduction by Salt Marshes." Submitted to PNAS, Aug. 2020. 


\section{Model Validation for Simulation of Wave Attenuation in Laboratory}

The CSHORE-Vegetation model with the proposed $C_{D}$ formulation (Equation 18) was validated by simulating the wave attenuation due to flexible, idealized vegetation measured in a wave flume by Anderson and Smith (2014). The experimental vegetation patch in the flume was built using polyolefin tubes, which can model the flexibility of Spartina alterniflora. This flume measured $63.4 \mathrm{~m}$ long, $1.5 \mathrm{~m}$ wide, and $1.5 \mathrm{~m}$ deep. The $9.8 \mathrm{~m}$ long vegetation field started approximately $26.9 \mathrm{~m}$ from the wave paddle. There were eight gages inside the vegetation patch (i.e., Gages 6 to 13 shown on Figure1 of Anderson and Smith [2014]). They provide a comprehensive dataset of laboratory experiments that cover experimental conditions of emergent $\left(\frac{h_{v}}{h}=1.36\right)$, near-emergent $\left(\frac{h_{v}}{h}=0.91\right)$, and submerged vegetation $\left(\frac{h_{v}}{h}=0.78\right)$. Table 3 presents the basic properties of the vegetation in the experiments. The flexural rigidity $(E I)$ is close to the mean value observed in section W2-W3 of the salt marsh in Terrebonne Bay (Table 2). The irregular incident waves in the flume were generated by using the TMA ${ }^{*}$ spectrum. The waves in all the tests were non-breaking as the ratio of significant wave height to depth ranges from 0.10 to 0.42 .

Even though no vegetation blades were modeled in the experiments, the flume layout and the collected wave gage data are useful for validating the CSHORE-Vegetation capacity for simulating wave attenuation due to flexible vegetation. Meanwhile, control tests without vegetation were also performed, which provides experimental data for calibrating other empirical parameters (e.g., bottom friction coefficient $f_{b}$ ) in the model, which are not associated with vegetation.

\footnotetext{
* named after three field data sets - Texel, MARSEN, and ARSLOE - used for the validation of the spectrum (Bouws et al. 1985)
} 
Table 3. Vegetation properties in laboratory experiments by Anderson and Smith (2014).

\begin{tabular}{|l|l|l|}
\hline Plant parameters & Unit & Value \\
\hline Population density (Nv) & {$[\mathrm{m}-2]$} & 200,400 \\
\hline Stem height (hv) & {$[\mathrm{m}]$} & 0.415 \\
\hline Total plant height (hvt) & {$[\mathrm{m}]$} & 0.415 \\
\hline Stem diameter (Bv) & {$[\mathrm{mm}]$} & 6.4 \\
\hline Young's modulus (E) & {$[\mathrm{MPa}]$} & 172.4 \\
\hline Second moment of inertia of stem (I) & {$[\mathrm{m} 4]$} & $8.23 \times 10-11$ \\
\hline Flexural rigidity (El) & {$[\mathrm{N}-\mathrm{m} 2]$} & 0.0142 \\
\hline
\end{tabular}

For model simulations, a 1-D computational grid was built up by aligning it with the wave flume from the edge of the vegetation patch and covering all the vegetation. Grid resolution was set to $0.02 \mathrm{~m}$. The empirical wave breaker index was 0.78. The newly developed $C_{D}$ curve (Equation 18) was used to estimate the drag coefficient of the flexible vegetation. The energy dissipation function (Equation 2) by Mendez and Losada (2004) was employed to calculate wave energy dissipation. The scaling law (Equation 7) was applied to calculate the effective stem heights. In addition to the vegetation property data in Table 3, the other parameters for the CSHOREVegetation model are listed in Table 4. Each simulation by CSHOREVegetation took only approximately $2 \mathrm{~s}$ to find steady solutions for waves and currents (i.e., mean velocity and water level profiles) on a standard laptop computer using a single Intel i7-865oU CPU@1.90GHz.

Table 4. Model parameters.

\begin{tabular}{|l|l|l|}
\hline Model Parameter & Unit & Value \\
\hline Grid size & {$[\mathrm{m}]$} & 0.02 \\
\hline Bottom friction factor $\left(f_{b}\right)$ & {$[1]$} & 0.160 \\
\hline Drag coefficient of vegetation $\left(C_{D}\right)$ & {$[1]$} & $\begin{array}{l}\text { Formulation } C_{D}(R e) \text { by Zhu et } \\
\text { al. }{ }^{*}\end{array}$ \\
\hline Energy dissipation $\left(D_{v}\right)$ & {$\left[\mathrm{J} / \mathrm{m}^{2} / \mathrm{s}\right]$} & $\begin{array}{l}\text { Equation }(2) \text { by Mendez and } \\
\text { Losada (2004) }\end{array}$ \\
\hline
\end{tabular}

All 30 experimental cases were simulated by CSHORE-Vegetation. For six selected tests with a near-emergent condition $\left(\frac{h_{v}}{h}=0.91\right)$, Figure 6 shows

\footnotetext{
* Zhu, L., Q. Chen, Y. Ding, J. Navid, H. Q. Wang, B. Johnson, and J. D. Rosati. In preparation. "Universal Relation of Drag Coefficient for Quantifying Wave Energy Reduction by Salt Marshes." Submitted to PNAS, Aug. 2020.
} 
the comparisons of $H_{r m s}$ between the simulated results and the experimental data. Three pairs of cases represent three types of incident waves: small $\left(H_{r m s o} \sim 3.4 \mathrm{~cm}\right)$, intermediate $(\sim 7.7 \mathrm{~cm})$, and large $(14.4 \mathrm{~cm})$. The three cases on the left panel are for the coarser vegetation $\left(N_{v}=200\right)$, and those on the right for the denser $\left(N_{v}=400\right)$. Using the $C_{D}(R e)$ formulation Equation (18) and the scaling law, the CSHORE-Vegetation model reproduces accurately the spatial distributions of wave heights through the species patch in response to varying vegetation flexibility and wave conditions. It also shows that the effective stem height (i.e., $h_{e} / h_{v}$ ) is decreased as the incident wave energy increases. It means that based on the scaling law, large waves can scale up the relative flexibility and then weaken the vegetation's ability to reduce the wave energy.

Figure 6. (a)-(f): Comparisons of profiles of wave heights $\left(\mathrm{H}_{r m s}\right)$ through the vegetation patch $(x=0.0 \sim 9.8 \mathrm{~m})$.

(a)

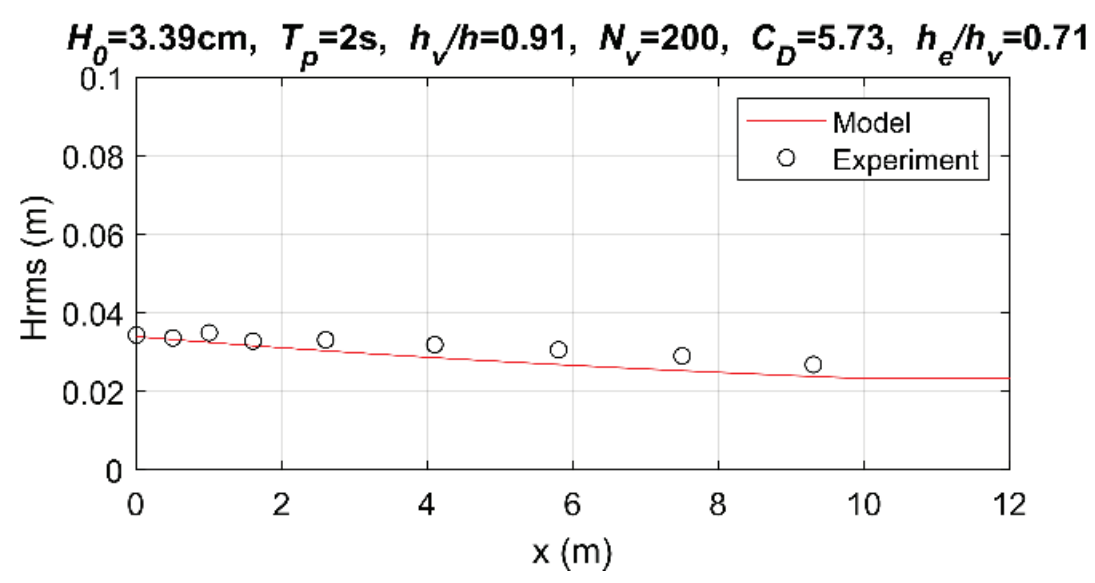

(b)

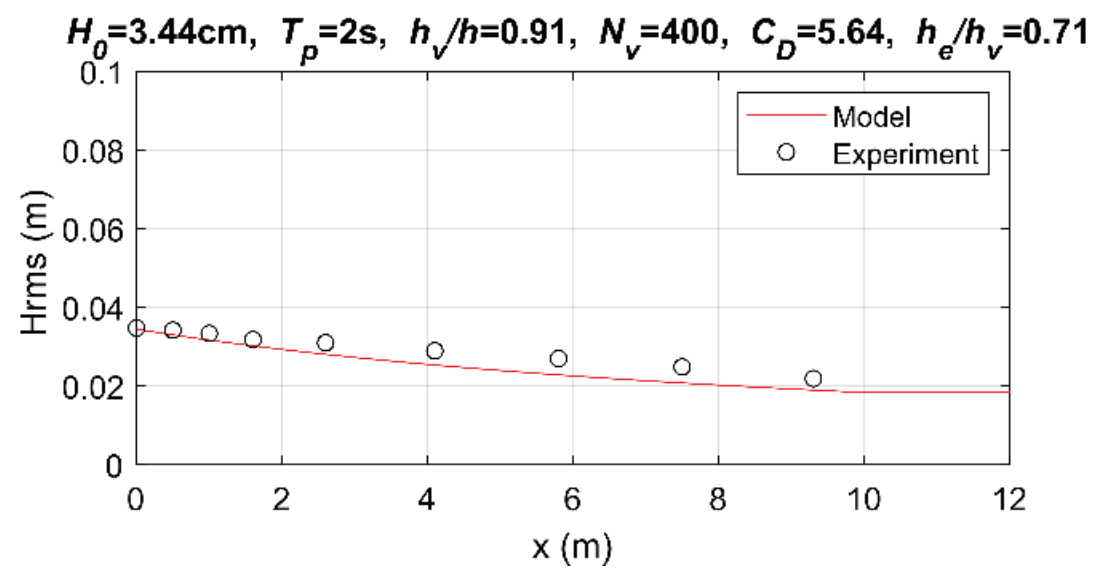


Figure 6. Continued.

(c) $\quad H_{0}=7.72 \mathrm{~cm}, T_{p}=1.5 \mathrm{~s}, h_{V} / h=0.91, N_{v}=200, C_{D}=3.58, h_{e} / h_{v}=0.55$

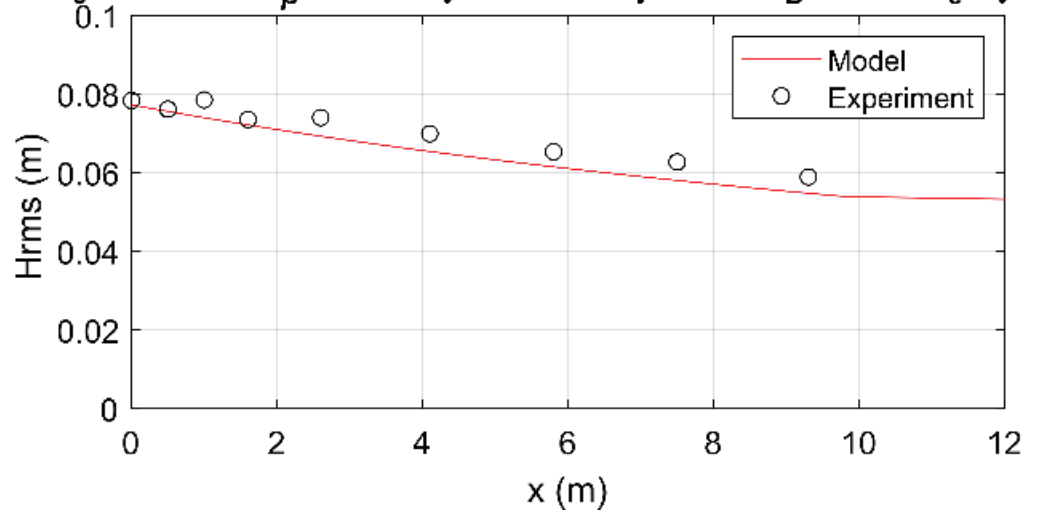

(d)

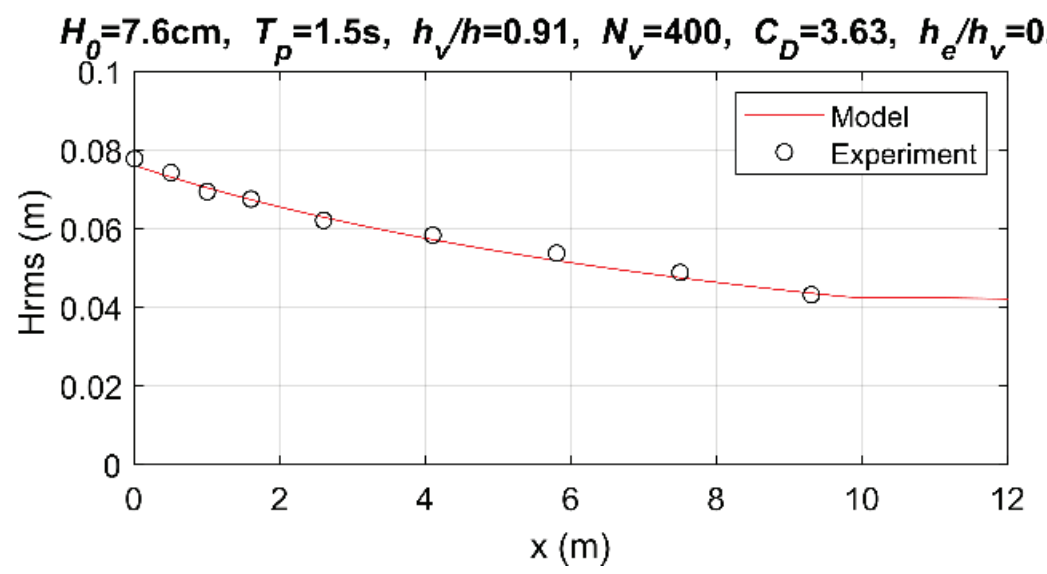

(e) $\quad H_{0}=14.4 \mathrm{~cm}, T_{p}=2 \mathrm{~s}, h_{v} / h=0.91, N_{v}=200, C_{D}=1.59, h_{e} / h_{v}=0.50$

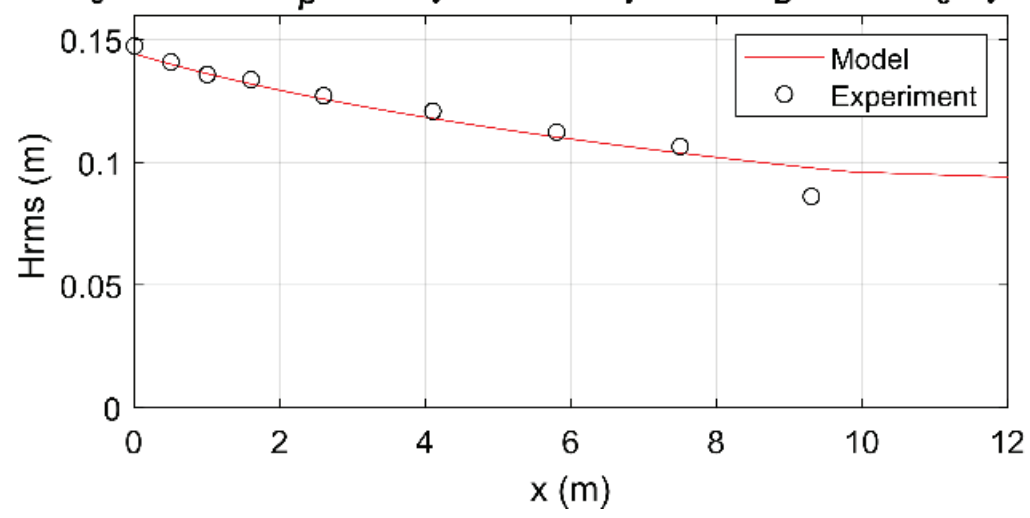


Figure 6. Continued.

(f)

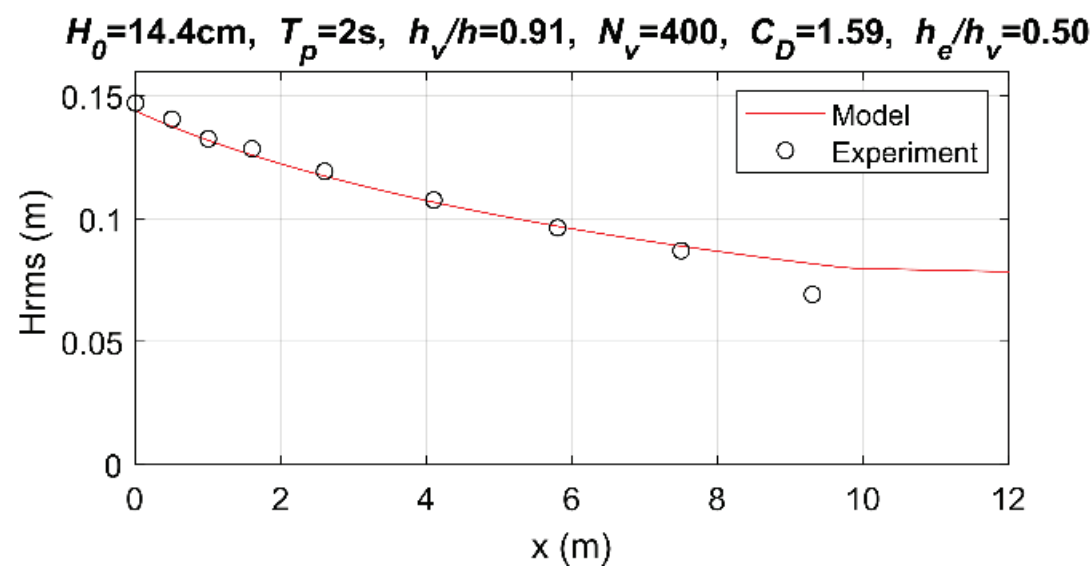

For all 27 validation cases with a total of 240 data points, Figure 7 presents a quantile-quantile plot for the simulated root-mean-square wave heights and observed values that were measured at all eight gages inside the vegetation patch (i.e., Gages 6 to 13). A small normalized root-meansquare deviation $(\mathrm{NRMSD}=0.044)$ and a close-to-unity $\mathrm{R}^{2}$ value (0.982) were obtained.

Figure 7. Observed vs. computed $\boldsymbol{H}_{r m s}$ at all the gages and for all the 27 experiments. ( $R^{2}=$ Coefficient of Determination, NRMSD $=$ Normalized Root-MeanSquare Deviation from the mean observed $\boldsymbol{H}_{\boldsymbol{r m s}}$ ).

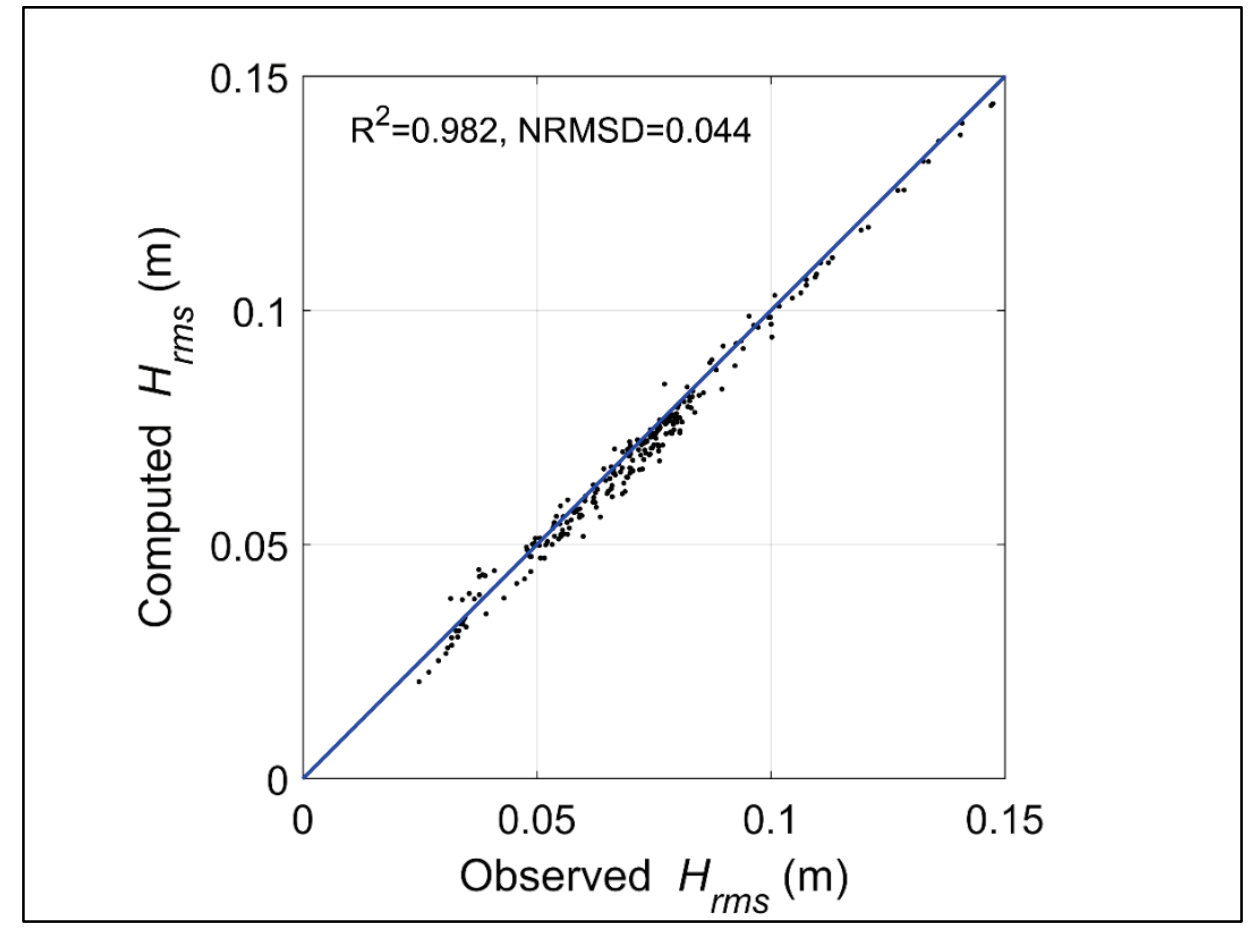




\section{Conclusions and Recommendations}

\subsection{Conclusions}

This technical report presents the development of a semi-empirical and data-driven numerical model (CSHORE-Vegetation) for predicting wave energy dissipation and flood level changes through marshes or vegetated coasts. The new capabilities for simulating flexible vegetation were implemented by formulating the relationship between vegetation resistance with its biomechanical properties such as density, dimension, flexibility/rigidity of stem and blades, bending, etc. In terms of the scaling law (Lei and Nepf 2019), species-specific responses to wave attenuation and resistance are characterized by the effective stem/blade heights and wave conditions. By using the field data of waves and properties of salt marsh in Terrebonne Bay, LA, a new formulation of the vegetation drag coefficient $\left(C_{D}\right)$ (Equation 18) (Zhu et al. 2020) was developed through regression analysis of the calibrated $C_{D}$ values at the site. Preliminary validation of the new $C_{D}$ regression formulation was achieved by simulating a set of laboratory experiments on flexible vegetation (Anderson and Smith 2014), which mimicked the flexibility of Spartina alterniflora. It shows the effectiveness of the new $C_{D}$ formulation for simulating wave energy dissipation and flow resistance in response to species-specific biomechanical features. This capability for flexible vegetation will enable the CSHORE-Vegetation model to quantify flood protection benefits of different types of vegetation and eventually to predict variation of vegetation resilience in locations and times.

\subsection{Recommendations}

As the capability for simulating vegetation has been implemented into the CSHORE model, when running the model for wave simulations, users still can refer to the user manual (e.g., Johnson et al. 2012). However, for setting up the CSHORE-Vegetation model, users must select a vegetation model, of which the indices and the model control variables are briefly described in the Appendix. Although a Python-based user interface for pre- and post-processing of the model is still under development, users are recommended to directly contact the authors for technical support of using CSHORE-Vegetation. 
As for future development of the research and its applications, work must continue on the two aspects: one is for technical transfer, and another for applicability to large-scale engineering problems. Technical transfer is a key to succeed in applications of the research results (models, data, and knowledge), partially because the developed techniques (numerical models) are parametric semi-empirical models and relatively new. Thus, it is imperative to accomplish the development of the Python-based user interface and to provide users with a user-friendly graphic interface. Documentations for technical report, user manual, training materials (tutorials, webinars, website/wiki, etc.) also have to be completed. Second, to provide solutions covering large-scale wetlands, there is a need to develop multidimensional vegetation simulation models to compute spatially varying wave fields across a large-scale wetland. There is also a need to advance the research on development of data-driven empirical models/formulations based on continuous field observation data on changes of biomechanical properties of marshes, morphological changes of wetlands, and hydrodynamic forcing. Furthermore, it is also critical to demonstrate the model and the developed procedure to study the effects of episodic events (cold storms, hurricanes) on marshes and vegetated coasts for understanding fragile and damage of vegetation. 


\section{References}

Anderson, M. E., and J. M. Smith. 2014. "Wave Attenuation by Flexible, Idealized Salt Marsh Vegetation.” Coastal Engineering 83: 82-92.

Baron-Hyppolite, C., C. H. Lashley, J. Garzon, T. Miesse, C. Ferreira, and J. D. Bricker. 2019. "Comparison of Implicit and Explicit Vegetation Representations in SWAN Hindcasting Wave Dissipation by Coastal Wetlands in Chesapeake Bay." Geosciences 9(8).

Bendoni, M., I. Y. Georgiou, D. Roelvink, and H. Oumeraci. 2019. "Numerical Modeling of the Erosion of Marsh Boundaries Due to Wave Impact." Coastal Engineering 152: 103514. https://doi.org/10.1016/i.coastaleng.2019.103514

Bouws, E., H. Giinther, W. Rosenthal, and C.L. Vincent. 1985. "Similarity of the Wind Wave Spectrum in Finite Depth Water. Part 1: Spectral Form.” J. Geophysical Research 90(C1): 975-986.

Bridges, T. S., P. W. Wagner, K. A. Burks-Copes, M. E. Bates, Z. A. Collier, C. J. Fischenich, J. Z. Gailani, L. D. Leuck, C. D. Piercy, J. D. Rosati, E. J. Russo, D. J. Shafer, B. C. Suedel, E. A. Vuxton, and T. V. Wamsley. 2015. Use of Natural and Nature-Based Features (NNBF) for Coastal Resilience. ERDC SR-15-1. Vicksburg, MS: US Army Engineer Research and Development Center.

Brown, D. P. 2011. Tropical Cyclone Report Tropical Storm Lee (AL132011), 2-5 September 2011. National Hurricane Center, 15 December 2011. https://www.nhc.noaa.gov/data/tcr/AL132011_Lee.pdf

Chen, Q., and H. Zhao. 2012. "Theoretical Models for Wave Energy Dissipation Caused by Vegetation." Journal of Engineering Mechanics 138(2): 221-229.

Chen, Q., N. H. Jafari, and L. Zhu. 2017. "Numerical Modeling to Determine the Capacity of Vegetated Shorelines to Reduce Coastal Erosion, Inundation, and Winds with Consideration of Long-Term Change in Sea Level. Part I." Annual Report for the US Army Corps of Engineers, Engineering Research and Development Center. Baton Rouge, LA: Louisiana State University.

Chen, Q. J., N. Jafari, and L. Zhu. 2019. “Updating USACE's Nearshore Coastal Numerical Model, CSHORE, to Calculate Benefits of Vegetated Shorelines." Annual Project Status Report (August 2018 - July 2019) for the US Army Corps of Engineers Engineering Research and Development Center. Northeastern University.

Dalrymple, R. A., J. T. Kirby, and P. A. Hwang. 1984. "Wave Diffraction Due to Areas of Energy Dissipation.” J. Waterw. Port Coast. Ocean Eng. 110(1): 67-79.

Dean, R. G., and C. J. Bender. 2006. "Static Wave Setup with Emphasis on Damping Effects by Vegetation and Bottom Friction.” Coastal Engineering 53: 149-156.

Ding, Y., J. D. Rosati, L. Zhu, and Q. Chen. 2019a. "Modeling Wave Attenuation and Runup in Wetland and Vegetated Coast." Proceedings of the ASCE-EWRI 2018 Congress, June 3-7, 2019, Pittsburg, PA. 
Ding, Y., M. Owensby, L. Zhu, Q. Chen, and B. Johnson. 2019b. "Modeling Wave Attenuation and Runup Due to Wave-Current-Vegetation Interaction." Proceedings of Coastal Sediment 2019, May 27-31, 2019, Tampa.

Dubi, A. 1995. Damping of Water Waves by Submerged Vegetation: A Case Study on Laminaria hyperborean." PhD thesis. University of Trondheim, The Norwegian Institute of Technology, Trondheim, Norway.

Hasselmann, D. E., M. Dunckel, and J. A. Ewing. 1980. "Directional Wave Spectra Observed during JONSWAP 1973.” J. Phys. Oceanogr. 10: 1264-1280.

Jadhav, R. S. 2012. Field Investigation of Wave and Surge Attenuation in Salt Marsh Vegetation and Wave Climate in a Shallow Estuary. PhD thesis. Louisiana State University.

Jadhav, R., and Q. Chen. 2012. "Field Investigation of Surge and Wave Propagation over Salt-Marsh during a Tropical Cyclone." Proceedings of the 33rd International Conference on Coastal Engineering, Spain.

Jadhav, R. S., Q. Chen, and J. M. Smith. 2013. "Spectral Distribution of Wave Energy Dissipation by Salt Marsh Vegetation." Coast. Eng. 77: 99-107.

Johnson, B., N. Kobayashi, and M. Gravens. 2012. Cross-Shore Numerical Model CSHORE For Waves, Currents, Sediment Transport, and Beach Profile Evolution. ERDC/CHL TR-12-22. Vicksburg, MS: US Army Engineer Research and Development Center.

Kobayashi, N., A. W. Raichle, and T. Asano. 1993. "Wave Attenuation by Vegetation.” $J$. Waterw. Port Coast. Ocean Eng. 119(1): 30-48.

Lei, J., and H. Nepf. 2019. "Wave Damping by Flexible Vegetation: Connecting Individual Blade Dynamics to the Meadow Scale." Coastal Engineering 147: 138-148.

Leonard, L. A., and M. E. Luther. 1995. "Flow Hydrodynamics in Tidal Marsh Canopies." Limnology and Oceanography 40(8): 1474-1484.

Leonardi, N., I. Carnacina, C. Donatelli, N. K. Ganju, A. J. Plater, M. Schuerch, and S. Temmerman. 2018. "Dynamic Interactions between Coastal Storms and Salt Marshes: A Review.” Geomorphology 301: 92-107. https://doi.org/10.1016/i.geomorph.2017.11.001

Mendez, F. J., and I. J. Losada. 2004. "An Empirical Model to Estimate the Propagation of Random Breaking and Non-Breaking Waves over Vegetation Fields." Coastal Eng. 51: 103-118.

Nepf, H. 1999. "Drag, Turbulence, and Diffusion in Flow through Emergent Vegetation." Water Resources Research 352: 479-489.

Rupprecht, F., I. Möller, M. Paul, M. Kudella, T. Spencer, B. K. van Wesenbeeck, G. Wolters, K. Jensen, T. J. Bouma, M. Miranda-Lange, and S. Schimmels. 2017. "Vegetation-Wave Interactions in Salt Marshes under Storm Surge Conditions." Ecol. Eng. 100: 301-315. 
Smith, J. M., M. A. Bryant, and T. V. Wamsley. 2016. "Wetland Buffers: Numerical Modeling of Wave Dissipation by Vegetation." Earth Surf. Process. Landf. 41: 847-854.

SWAN. 2020. Swan-Scientific and Technical Documentation for Swan Cycle II, version 41.31A, Section 2.4. "Wave Damping Due to Vegetation." The Netherlands: Delft University of Technology. http://www.swan.tudelft.nl

XBEACH. 2020. XBEACH User Manual. https://xbeach.readthedocs.io/en/latest/xbeach_manual.html\#waves

Zhu, L., and Q. Chen. 2019. "Phase-Averaged Drag Force of Nonlinear Waves over Submerged and through Emergent Vegetation.” Journal of Geophysical Research: Oceans 124.

Zhu, L., Q. J. Chen, N. Jafari, J. D. Rosati, and Y. Ding. 2018. "Modeling Effects of Vegetation on Setup and Runup of Random Waves." Coastal Engineering Proceedings 1(36). https://doi.org/10.9753/icce.v36.currents.8

Zhu, L., Q. Chen, Y. Ding, N. Jafari, and J. D. Rosati. 2019. "A Semi-Analytical Model of Depth-Integrated Vegetal Drag Force Based on Stokes Second-Order Wave Theory." Journal of Waterway, Port, Coastal and Ocean Engineering 145(2): 04018041. 


\section{Appendix: Control Variables of CSHORE- Vegetation for Selecting Model Capabilities}

This appendix provides additional information on the new model capabilities, which can be selected by giving specific values of the CSHORE-Vegetation control variables (e.g., IVEG) when configuring the CSHORE-Vegetation input file. Table 5 gives descriptions of the optional values of the control variables for specifying the calculation approach, input conditions, and vegetation features.

Table 5. Control variables and optional values for selecting the model vegetation capabilities.

\begin{tabular}{|l|l|l|}
\hline Variable Name & Optional Value & Descriptions \\
\hline IVEG $=$ & 0 & No vegetation \\
\hline & 1 & $\begin{array}{l}\text { For vegetation whose density, width, height, and root } \\
\text { depth are specified as input. The height and root } \\
\text { depth vary with the bottom elevation change. }\end{array}$ \\
\hline & 2 & $\begin{array}{l}\text { For vegetation whose constant density, width, and } \\
\text { height are specified as input. }\end{array}$ \\
\hline IDISS $=$ & 3 & $\begin{array}{l}\text { For vegetation whose density, width, height, and root } \\
\text { depth are specified as input. User can select energy } \\
\left.\text { dissipation model ( } D_{v}\right) \text { and the drag resistance }\left(F_{v}\right) \\
\text { the phase-averaged depth-integrated momentum } \\
\text { equation. This is the default option to use the newly } \\
\text { implemented features of vegetation described in this } \\
\text { technical report. }\end{array}$ \\
\hline & 1 & $\begin{array}{l}D_{v} \text { is calculated by Equation (2) (Mendez and Losada } \\
\text { 2004). }\end{array}$ \\
\hline & 2 & $\begin{array}{l}D_{v} \text { is calculated using the formulation developed by } \\
\text { Chen and Zhao (2012) with the JONSWAP spectrum. }\end{array}$ \\
\hline IFV $=$ & $\begin{array}{l}D_{v} \text { is calculated using the formulation developed by } \\
\text { Chen and Zhao (2012) with a user-input spectrum. }\end{array}$ \\
\hline & 3 & $\begin{array}{l}\text { The original approach to calculate } F_{v} \text { (Chen et al. } \\
\text { 2017). }\end{array}$ \\
\hline & 2 & $\begin{array}{l}F_{v} \text { calculated by Equation (5) for both submerged and } \\
\text { emergent vegetation (Zhu and Chen 2019) (the } \\
\text { default option). }\end{array}$ \\
\hline $\begin{array}{l}F_{v} \text { calculated by a hybrid model for both submerged } \\
\text { and emergent vegetation (Zhu et al. 2018). }\end{array}$ \\
\hline
\end{tabular}




\section{Unit Conversion Factors}

\begin{tabular}{|c|c|c|}
\hline Multiply & By & To Obtain \\
\hline feet & 0.3048 & meters \\
\hline inches & 0.0254 & meters \\
\hline miles (nautical) & 1,852 & meters \\
\hline miles (US statute) & $1,609.347$ & meters \\
\hline miles per hour & 0.44704 & meters per second \\
\hline mils & 0.0254 & millimeters \\
\hline square feet & 0.09290304 & square meters \\
\hline square inches & $6.4516 \mathrm{E}-04$ & square meters \\
\hline square miles & $2.589998 E+06$ & square meters \\
\hline square yards & 0.8361274 & square meters \\
\hline yards & 0.9144 & meters \\
\hline
\end{tabular}




\section{Acronyms and Abbreviations}

$\begin{array}{ll}\text { 1-D } & \text { One-dimensional } \\ \text { CHL } & \text { Coastal and Hydraulics Laboratory } \\ \text { EBH } & \text { Effective blade heights } \\ \text { ERDC } & \text { US Army Engineer Research and Development Center } \\ \text { ESH } & \text { Effective stem height } \\ \text { JONSWAP } & \text { Joint North Sea Wave Project } \\ \text { KC } & \text { Keulegan-Carpenter number } \\ \text { MWL } & \text { Mean water level } \\ \text { MWSE } & \text { Mean water surface elevation } \\ \text { Re } & \text { Reynolds number } \\ \text { SWL } & \text { Still water level }\end{array}$




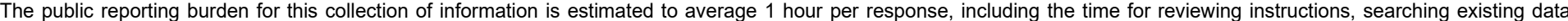

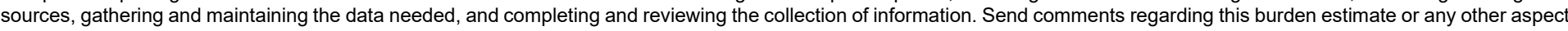

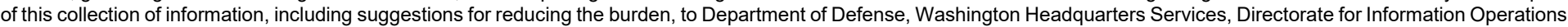

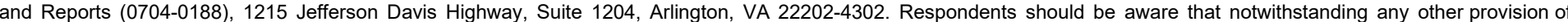
law, no person shall be subject to any penalty for failing to comply with a collection of information if it does not display a currently valid OMB control number. PLEASE DO NOT RETURN YOUR FORM TO THE ABOVE ADDRESS.

\begin{tabular}{l|l|l}
\hline $\begin{array}{l}\text { 1. REPORT DATE } \\
\text { February } 2022\end{array}$ & $\begin{array}{l}\text { 2. REPORT TYPE } \\
\text { Final Report }\end{array}$ & 3. DATES COVERED (FrOm - To)
\end{tabular}

\section{TITLE AND SUBTITLE}

Implementation of Flexible Vegetation into CSHORE for Modeling Wave Attenuation 5a. CONTRACT NUMBER

5b. GRANT NUMBER

5c. PROGRAM ELEMENT NUMBER

6. AUTHOR(S)

Yan Ding, Q. Jim Chen, Ling Zhu, Julie Dean Rosati, and Bradley D. Johnson

\section{5d. PROJECT NUMBER}

5e. TASK NUMBER

5f. WORK UNIT NUMBER

\section{PERFORMING} ORGANIZATION REPORT NUMBER Engineering and Department of Marine and Environmental Sciences Northeastern University

ERDC/CHL TR-22-2 471 Snell Engineering Center 360 Huntington Ave.
Coastal and Hydraulics Laboratory

US Army Engineer Research and

Development Center

3909 Halls Ferry Road

Vicksburg, MS 39180-6199
Boston, MA 02115

\section{SPONSORING/MONITORING AGENCY NAME(S) AND ADDRESS(ES)}

USACE Flood and Coastal Systems Program

US Army Engineer Research and Development Center

Coastal and Hydraulics Laboratory

Vicksburg, MS 39180-6199
10. SPONSOR/MONITOR'S ACRONYM(S) USACE FCSP

\section{SPONSOR/MONITOR'S} REPORT NUMBER(S)

\section{DISTRIBUTION/AVAILABILITY STATEMENT}

Approved for public release; distribution is unlimited.

\section{SUPPLEMENTARY NOTES}

Funding Account Code 39JK18, AMSCO Code 060000

\section{ABSTRACT}

This technical report presents the new numerical modeling capabilities for simulating wave attenuation and mean water level changes through flexible vegetation such as smooth cordgrass in coastal and marine wetlands. These capabilities were implemented into the Cross-SHORE (CSHORE) numerical model. The biomechanical properties of vegetation such as dimensions, flexibility, and bending strength are parameterized in terms of the scaling law. Correspondingly, a new formulation of the vegetation drag coefficient, CD, is developed using field data from a salt marsh in Terrebonne Bay, LA, by considering spatially varying effective stem and blade heights of species. This report also presents a general procedure for using the model to simulate hydrodynamic variables (i.e., waves, currents, mean water levels) at vegetated coasts, which are used to quantify the effects of wave attenuation and reduction of surge and runup due to vegetation. Preliminary model validation was conducted by simulating a set of laboratory experiments on synthetic vegetation, which mimicked the flexibility of Spartina alterniflora. The validation results indicate that the newly developed vegetation capabilities enable CSHORE to predict changes of wave heights and water levels through marshes by considering species-specific biomechanical features. The model is also applicable to assess vegetation effectiveness against waves and surges.

\section{SUBJECT TERMS}

Coastal plants - Effect of water levels on, Hydrodynamics, Salt marshes, Mathematical models, Water levels, Water wavesAttenuation, Wetlands

\section{SECURITY CLASSIFICATION OF:}

\begin{tabular}{|l|l|l|} 
a. REPORT & b. ABSTRACT & c. THIS PAGE \\
Unclassified & Unclassified & Unclassified \\
\hline
\end{tabular}

17. LIMITATION OF ABSTRACT

SAR
18. NUMBER OF PAGES

39 19a. NAME OF RESPONSIBLE PERSON Yan Ding

19b. TELEPHONE NUMBER (Include area code) 601-634-5374 